\title{
Development and application of a backscatter lidar forward operator for quantitative validation of aerosol dispersion models and future data assimilation
}

\author{
Armin Geisinger $^{1}$, Andreas Behrendt ${ }^{1}$, Volker Wulfmeyer ${ }^{1}$, Jens Strohbach ${ }^{1}$, Jochen Förstner ${ }^{2}$, and Roland Potthast ${ }^{2}$ \\ ${ }^{1}$ Institute of Physics and Meteorology, University of Hohenheim, Stuttgart, Germany \\ ${ }^{2}$ Headquarter of the German Weather Service, Offenbach, Germany
}

Correspondence to: Armin Geisinger (armin.geisinger@uni.hohenheim.de)

Received: 2 May 2017 - Discussion started: 17 May 2017

Revised: 14 September 2017 - Accepted: 6 October 2017 - Published: 5 December 2017

\begin{abstract}
A new backscatter lidar forward operator was developed which is based on the distinct calculation of the aerosols' backscatter and extinction properties. The forward operator was adapted to the COSMO-ART ash dispersion simulation of the Eyjafjallajökull eruption in 2010. While the particle number concentration was provided as a model output variable, the scattering properties of each individual particle type were determined by dedicated scattering calculations. Sensitivity studies were performed to estimate the uncertainties related to the assumed particle properties. Scattering calculations for several types of non-spherical particles required the usage of T-matrix routines. Due to the distinct calculation of the backscatter and extinction properties of the models' volcanic ash size classes, the sensitivity studies could be made for each size class individually, which is not the case for forward models based on a fixed lidar ratio. Finally, the forward-modeled lidar profiles have been compared to automated ceilometer lidar (ACL) measurements both qualitatively and quantitatively while the attenuated backscatter coefficient was chosen as a suitable physical quantity. As the ACL measurements were not calibrated automatically, their calibration had to be performed using satellite lidar and ground-based Raman lidar measurements. A slight overestimation of the model-predicted volcanic ash number density was observed. Major requirements for future data assimilation of data from ACL have been identified, namely, the availability of calibrated lidar measurement data, a scattering database for atmospheric aerosols, a better representation and coverage of aerosols by the ash dispersion model, and more investigation in backscatter lidar forward operators which calculate the backscatter coefficient
\end{abstract}

directly for each individual aerosol type. The introduced forward operator offers the flexibility to be adapted to a multitude of model systems and measurement setups.

\section{Introduction}

In spring 2010, the Icelandic volcano Eyjafjallajökull erupted several times. The emitted ash was found to be harmful for aircraft, and due to uncertain information about spatial distribution and concentration of volcanic ash, the European air space was closed for several days (Sandrini et al., 2014). The high economic costs and impact on public transport led to efforts of DWD (Deutscher Wetterdienst) to improve monitoring and predicting ash plumes in the atmosphere. Therefore, DWD decided to start a dedicated project on backscatter lidar forward operators for validating aerosol dispersion models using available remote-sensing measurement data and for future assimilation of lidar backscatter and extinction data.

Atmospheric chemistry models which allow for aerosol dispersion predictions are, amongst others, COSMO-ART (Consortium for Small-scale Modeling, Aerosols and Reactive Trace gases; Vogel et al., 2009), COSMO-MUSCAT (Multiscale Chemistry Aerosol Transport; Wolke et al., 2004), ECMWF (European Centre for Medium-Range Weather Forecasts; Benedetti, 2009), ENVIRO-HIRLAM (Environment - High Resolution Limited Area Model; Zakey et al., 2006), MACC-II (Monitoring Atmospheric Composition and Climate - Interim Implementation; Cuevas et al., 2015), MCCM (Multiscale Coupled Chemistry Model; 
Emeis et al., 2011), MesoNH (Non-Hydrostatic Mesoscale Atmospheric Model of the French Research Community; Mallet et al., 2009), and WRF-CHEM (Weather Research and Forecast Model; Chen et al., 2014). Using these model systems, scientists have analyzed the aerosol influence on, for example, precipitation (Rieger et al., 2014), temperature (Bangert et al., 2012), radiative fluxes (Vogel et al., 2009), and convection initiation (Chaboureau et al., 2011). These models are potentially capable of simulating such ash dispersion scenarios and could thus benefit from the methodology presented here.

Lidar (light detection and ranging) is capable of providing information on atmospheric particles with high temporal and spatial resolution. The most basic lidar type is the backscatter lidar which measures the backscattered signal intensity of a volume at a certain range. Comparing the data of such a backscatter lidar that is operated in the UV with simulations of an atmospheric chemistry model allows for the characterization of transport and optical properties of aerosol particles near sources (Behrendt et al., 2011; Valdebenito B et al., 2011). Using ground-based DIAL (differential absorption lidar; Weitkamp, 2008; Späth et al., 2016) water-vapor can be measured, which can even be combined with backscatter measurements to derive more details of aerosol particle properties (Wulfmeyer and Feingold, 2000). Lidar techniques based on the vibrational and rotational Raman effect, like RRL (rotational Raman lidar) allow for the measurement of trace gas profiles (Whiteman et al., 1992; Turner et al., 2002; Wulfmeyer et al., 2010; Haarig et al., 2016) as well as profiles of atmospheric temperature, particle backscatter cross section, particle extinction cross section, and particle depolarization properties (Behrendt et al., 2002; Hammann et al., 2015; Radlach et al., 2008). High-spectral-resolution lidar (HSRL) systems furthermore allow for cloud and particle characterization (Shipley et al., 1983). Multi-wavelength lidar systems offer the potential to retrieve the optical, microphysical, and chemical properties of aerosols (Mamouri et al., 2012), but these systems are rare and the inversion algorithms are very complex. Profiles of the radial wind speed can be obtained by using Doppler-lidar systems (see, e.g., Banta et al., 2012).

While the number of sophisticated lidar instruments that provide thermodynamic data (Wulfmeyer et al., 2015) is still low, there are already automated aerosol lidar networks in operation in Europe and Asia (Pappalardo et al., 2014; Sugimoto et al., 2008). The data of such networks offer 3-D particle information with high temporal and vertical and moderate horizontal resolution. Automated ceilometer lidar systems (ACLs) have been used to detect cloud and boundary layer heights (Emeis et al., 2009) but the received signal also delivers information about aerosols. It is therefore worthwhile to use the ACL network measurements for the validation of particle transport model simulations. Unfortunately, it is not possible to obtain the particle number concentration from an elastic backscatter signal alone without ancillary information and assumptions which are partly critical. The alternative is to use the detailed atmospheric description of the model to simulate lidar profiles for a model-given atmospheric state. Such a lidar simulator is called a lidar forward operator. Using an ideal lidar forward operator, the signal of a given lidar system can be calculated from the model prediction at any time interval, grid location, and measurement direction.

There are already several backscatter lidar forward operators available or in development which are based on the calculation of the extinction coefficient. The backscatter coefficient is then calculated assuming a given lidar ratio $S_{\text {lidar }}$ (Benedetti, 2009; Morcrette et al., 2009; Sič, 2014; CharltonPerez et al., 2013; Lange and Elbern, 2014). On the one hand, this method benefits from the fact that the extinction coefficient is less sensitive to the particle dimension and shape than the backscatter coefficient. On the other hand, the precision of this method is limited to the correctness of assumed lidar ratio values. The method becomes unusable once there is a mixture of scatterers.

We designed a forward operator which is based on the distinct calculation of extinction and the backscatter coefficients in the model system. This forward operator can be adapted to particle-representing atmospheric model and backscatter lidar systems even using multiple wavelengths. It has the capability to calculate both the attenuated backscatter coefficient and the lidar ratio from model output data with a minimum set of external information. The name of the forward model is "backscatter lidar forward operator" (BaLiFOp).

In the following we explain the lidar principles and the theoretical background for the backscatter lidar forward operator (Sect. 2). This is followed by an introduction to the case study in Sect. 3. Sensitivity studies of the particles' scattering properties are presented in Sect. 4. Results of the forward operator and a comparison to ACL measurement data are shown in Sect. 5. Finally, we summarize the results of our study and discuss both the benefits and the requirements of current and future lidar data assimilation systems (Sect. 6).

\section{Methods}

\subsection{The lidar equation}

The lidar principle is based on the emission of laser pulses into the atmosphere and the measurement and analysis of the backscatter signals. The received photon number per pulse $N_{\text {rec, } \lambda}(z)$ from range $z$ is described by the following equation for elastic backscatter lidars which detect the backscatter signal at the emitted wavelength:

$$
\begin{aligned}
& N_{\text {rec }, \lambda}(z)= \\
& N_{\text {tr }, \lambda} \frac{\tau c}{2} \eta_{\lambda} O(z) \frac{A_{\text {tel }}}{z^{2}} \beta_{\lambda}(z) \exp \left(-2 \int_{0}^{z} \alpha_{\lambda}\left(z^{\prime}\right) \mathrm{d} z^{\prime}\right) .
\end{aligned}
$$


Instrument-dependent variables of the lidar equation are the wavelength $\lambda$, the laser emitted photon number per pulse $N_{\mathrm{tr}, \lambda}$, the temporal length of a laser pulse $\tau$, the efficiency of the receiving system and detectors $\eta_{\lambda}$, the overlap function $O(z)$, and the net area of the receiving telescope $A_{\text {tel }}$. The received signal intensity can be given either as power or in photon counts. Here, we use photon counts per laser pulse unless otherwise noted.

The range resolution is usually matched to the temporal resolution of the data acquisition system by $\frac{\tau c}{2}=\Delta z$ with $c$ as speed of light. Typical $\Delta z$ values for ACL systems are a few meters. The overlap function $O(z)$ is 0 (no overlap) near the ground and becomes 1 (full overlap) above a certain height, which is typically 200 to $1500 \mathrm{~m}$ above ground for ACL systems (Wiegner et al., 2014; Flentje et al., 2010a). The missing overlap limits the capability to measure and calibrate in the near range but has no effect where full overlap has been accomplished. Heights where $0<O(z)<1$ can be overlap-corrected if the device-specific overlap function is known.

Processes in the atmosphere are described by the backscatter coefficient $\beta_{\lambda}(z)$ and the extinction coefficient $\alpha_{\lambda}(z)$. The backscatter coefficient $\beta_{\lambda}(z)$ describes the scattering strength into the direction of the receiving telescope and depends on wavelength, type, shape, and size of scatterers, and their respective number concentrations; $\beta_{\lambda}(z)$ is given in units of $\mathrm{m}^{-1} \mathrm{sr}^{-1}$. The extinction coefficient $\alpha_{\lambda}(z)$ is a description for laser radiation absorption and scattering capabilities of objects in a volume; it is given in units of $\mathrm{m}^{-1}$.

Elastic backscatter lidar systems do not allow for a separate measurement of $\beta_{\lambda}(z)$ and $\alpha_{\lambda}(z)$ as two unknowns cannot be determined with one measured variable. For calibrated backscatter lidar systems, it is thus convenient to calculate the attenuated backscatter coefficient $\gamma_{\lambda}(z)$ from the measured profiles:

$\gamma_{\lambda}(z)=\beta_{\lambda}(z) \exp \left(-2 \int_{0}^{z} \alpha_{\lambda}\left(z^{\prime}\right) \mathrm{d} z^{\prime}\right)$.

It is given in units of $\mathrm{m}^{-1} \mathrm{sr}^{-1}$. The attenuated backscatter coefficient is independent of all instrument-specific parameters except the wavelength. Therefore, it is the best suitable physical quantity for comparison between backscatter lidar measurement and aerosol model using a forward operator as long as no ACL measurements of extinction and backscatter cross section profiles are available for this purpose.

\subsection{The backscatter lidar forward operator}

According to Eq. (2), the basic functionality of the forward operator is the calculation of extinction coefficient $\alpha_{\lambda}(z)$ and backscatter coefficient $\beta_{\lambda}(z)$ based on a given atmospheric state and, finally, to determine the attenuated backscatter coefficient $\gamma_{\lambda}(z)$.

\subsubsection{Scattering of laser radiation by arbitrary objects}

The total extinction coefficient $\alpha_{\lambda}(z)$ and the total backscatter coefficient $\beta_{\lambda}(z)$ of an illuminated volume with $q_{s}$ different types of scatterers are calculated from

$$
\begin{aligned}
\alpha_{\lambda}(z) & =\sum_{i=1}^{q_{s}} \alpha_{i, \lambda}(z)=\sum_{i=1}^{q_{s}} \int_{0}^{\infty} n_{i}(R, z) \sigma_{\mathrm{ext}, i, \lambda}(R) \mathrm{d} R, \\
\beta_{\lambda}(z) & =\sum_{i=1}^{q_{s}} \beta_{i, \lambda}(z) \\
& =\sum_{i=1}^{q_{s}} \int_{0}^{\infty} n_{i}(R, z)\left(\frac{\mathrm{d} \sigma_{\mathrm{sca}, i, \lambda}(R)}{\mathrm{d} \Omega}\right)_{\pi} \mathrm{d} R,
\end{aligned}
$$

where $n_{i}(R, z)$ is the number-size distribution of scatterer type $i$ with radius $R$ at range $z$ given in units of $\mathrm{m}^{-3}, \sigma_{\mathrm{ext}, i, \lambda}$ is the corresponding extinction cross section given in units of $\mathrm{m}^{2}$, and $\left(\frac{\mathrm{d} \sigma_{\mathrm{sca}, i, \lambda}}{\mathrm{d} \Omega}\right)_{\pi}$ is the differential backscatter cross section given in units of $\mathrm{m}^{2} \mathrm{sr}^{-1}$.

For isotropic scattering, the differential backscatter cross section is derived from the scattering cross section $\sigma_{\mathrm{sca}, i, \lambda}(R)$ via

$$
\left(\frac{\mathrm{d} \sigma_{\mathrm{sca}, i, \lambda}(R)}{\mathrm{d} \Omega}\right)_{\pi}=\frac{\sigma_{\mathrm{sca}, i, \lambda}(R)}{4 \pi \mathrm{sr}} .
$$

For non-isotropic scattering, a phase function $\phi_{i, \lambda}(\theta, R)$ is used to describe the relative scattering intensity into angle $\theta$, which is $\pi$ for monostatic systems:

$$
\left(\frac{\mathrm{d} \sigma_{\mathrm{sca}, i, \lambda}(R)}{\mathrm{d} \Omega}\right)_{\pi}=\frac{\sigma_{\mathrm{sca}, i, \lambda}(R)}{4 \pi \mathrm{sr}} \phi_{i, \lambda}(\pi, R) .
$$

Molecule scattering and particle scattering are differentiated here, as the respective calculations depend on suitable physical theories and algorithms.

\subsubsection{Scattering by molecules}

For a model which is capable of distinguishing atmospheric gases such as nitrogen, oxygen, argon, and water vapor, the molecule scattering calculation could be performed for each individual gas type and molecule size using the Rayleigh theory (Young, 1981). For ACL systems, provided that a wavelength is used which is well outside of molecular absorption lines, the individual gas contribution to the signal does not need to be distinguished.

Consequently, the molecule extinction coefficient $\alpha_{\mathrm{mol}, \lambda}(z)$ and the molecule backscatter coefficient $\beta_{\mathrm{mol}, \lambda}(z)$ can be calculated with

$$
\begin{aligned}
& \alpha_{\mathrm{mol}, \lambda}(z)=N_{\mathrm{mol}, \lambda}(z) \sigma_{\mathrm{sca}, \mathrm{mol}, \lambda}, \\
& \beta_{\mathrm{mol}, \lambda}(z)=N_{\mathrm{mol}, \lambda}(z)\left(\frac{\mathrm{d} \sigma_{\mathrm{sca}, \mathrm{mol}, \lambda}}{\mathrm{d} \Omega}\right)_{\pi},
\end{aligned}
$$


where the molecule number density $N_{\mathrm{mol}}(z)$ is related to the ideal gas law

$N_{\text {mol }}(z)=\frac{p(z)}{k T(z)}$,

with $p$ as atmospheric pressure given in pascal $(\mathrm{Pa}), T$ as temperature given in kelvin (K), and $k$ as Boltzmann constant, which has a value of $1.38 \times 10^{-23} \mathrm{~J} \mathrm{~K}^{-1}$.

To calculate the scattering cross section $\sigma_{\mathrm{sca}, \mathrm{mol}, \lambda}$ and the scattering phase function $\phi_{\mathrm{a}, \lambda}(\theta)$ of air, we used the formulas and look-up tables given by Buchholtz (1995). As these empirical equations are only provided for wavelengths up to $1000 \mathrm{~nm}$, we simply extrapolated the values to the ACL wavelength in the case study $(1064 \mathrm{~nm})$.

\subsubsection{Scattering by particles}

The scattering characteristics of larger particles are described by Mie's solution of the Maxwell equations (Mie, 1908; Wiscombe, 1980). The T-matrix method (Mishchenko et al., 2002) or the discrete dipole approximation (DDA; Draine and Flatau, 1994) allow for calculating the scattering properties of non-spherical objects with sizes not much smaller or larger than the wavelength. The T-matrix method is a tool for computing scattering by single and compounded particles (Mishchenko et al., 2002). It is faster than DDA but limited to rotationally symmetric objects such as ellipsoids, cylinders, or Chebyshev polynomials. DDA, however, has the flexibility to represent arbitrarily shaped objects at the cost of high computational efforts.

As a rough estimate, the computational time increases by about 1 order of magnitude when using T-matrix instead of Mie scattering calculation routines and by another 2 orders of magnitude when using DDA instead of T-matrix. Another increase in computational time results from larger scatterers; i.e., an increase in the particle size results in an exponential increase in computing time. In this study, Mie scattering algorithms are therefore used to perform fast calculations. The effect of scattering by non-spherical particles is analyzed in a second step by T-matrix scattering calculations for several non-spherical particle shapes in the framework of sensitivity studies. This approach is required because the COSMO-ART volcanic plume simulation does not output any information about the particle shape distribution.

Mie scattering-related computations were performed using the IDL (Interactive Data Language) procedure "mie_single", provided by the Department of Atmospheric, Oceanic and Planetary Physics (AOPP), University of Oxford. Input parameters of the procedure are the real part $m$ and imaginary part $m^{\prime}$ of the refractive index as well as the so-called size parameter $X_{\lambda}(R)$ :

$X_{\lambda}(R)=\frac{2 \pi R}{\lambda}$,

where $R$ is the radius of a single particle. The relevant output parameters are the extinction efficiency $Q_{\text {ext }, p, \lambda}(R)$ and the backscatter efficiency $Q_{\mathrm{bsc}, p, \lambda}(R)$ of particle type $p$. These optical efficiencies are defined as ratio between the optical cross section and the physical cross section:

$Q_{\mathrm{ext}, p, \lambda}(R)=\frac{\sigma_{\mathrm{ext}, p, \lambda}(R)}{\pi R^{2}}$,

$Q_{\mathrm{bsc}, p, \lambda}(R)=\frac{\left(\frac{\mathrm{d} \sigma_{\mathrm{sca}, p, \lambda}(R)}{\mathrm{d} \Omega}\right)_{\pi}}{\pi R^{2}}$.

As a warning, we would like to point out that the procedure changed its definition of the backscatter efficiency: the 2012 release of mie_single returns the so-called radar backscatter efficiency, which is $4 \pi$ times the backscatter efficiency we require within the forward operator. Furthermore, the procedure expects the imaginary part of the refractive index given as negative number. If positive imaginary part values are used, the procedure runs without showing an error but returns wrong results.

\subsubsection{Discrete particle number size distributions}

A major problem of discrete size distributions is the high sensitivity of the optical cross sections to the particle size: a slightly different particle radius may lead to quite a large change of the scattering properties. We present in the following an approach to overcome this problem. Due to the fact that naturally occurring particle size distributions are not discrete, averaging the optical cross sections over certain sizeintervals seems straightforward. We will show that this approach indeed reduces the problematic and unrealistic sensitivity significantly. If the model represents only one type of particle, i.e., with a constant refractive index but with discrete radii $R_{d}$, we can define the effective extinction cross section and the effective backscatter cross sections with

$$
\begin{aligned}
& \overline{\sigma_{\mathrm{ext}, R_{d}, m, m^{\prime}, \lambda}}= \\
& \frac{1}{R_{d_{b}}-R_{d_{a}}} \int_{R_{d_{a}}}^{R_{d_{b}}} Q_{\mathrm{ext}}\left(X_{\lambda}\left(R_{d}\right), m, m^{\prime}\right) \pi R_{d}^{2} \mathrm{~d} R_{d}, \\
& \overline{\sigma_{\mathrm{bsc}, R_{d}, m, m^{\prime}, \lambda}}= \\
& \frac{1}{R_{d_{b}}-R_{d_{a}}} \int_{R_{d_{a}}}^{R_{d_{b}}} Q_{\mathrm{bsc}}\left(X_{\lambda}\left(R_{d}\right), m, m^{\prime}\right) \pi R_{d}^{2} \mathrm{~d} R_{d},
\end{aligned}
$$

where $R_{d_{a}}$ and $R_{d_{b}}$ are size margins for each particle size class $d$. These integrals are then exchanged with sums in the numerical computation routines.

The calculation of the effective values is performed for every discrete size class $d$ and - if represented by the model also for every particle type $k$. Consequently, the total particle extinction coefficient $\alpha_{\mathrm{par}, \lambda}(z)$ and the total particle backscatter coefficient $\beta_{\mathrm{par}, \lambda}(z)$ are calculated from 
$\alpha_{\mathrm{par}, \lambda}(z)=\sum_{k} \sum_{d} N_{d, k}(z) \overline{\sigma_{\mathrm{ext}, R_{d}, m_{k}, m_{k}^{\prime}, \lambda}}$,

$\beta_{\mathrm{par}, \lambda}(z)=\sum_{k} \sum_{d} N_{d, k}(z) \overline{\sigma_{\mathrm{bsc}, R_{d}, m_{k}, m_{k}^{\prime}, \lambda}}$.

Here, $N_{d, k}$ is the particle number per volume given by the model, $\overline{\sigma_{\text {ext }, R_{d}, m_{k}, m_{k}^{\prime}, \lambda}}$ and $\overline{\sigma_{\mathrm{bsc}, R_{d}, m_{k}, m_{k}^{\prime}, \lambda}}$ are the effective optical cross sections of particle size class $d$ and particle type class $k$ with the respective real part $m_{k}$ and imaginary part $m_{k}^{\prime}$ of the refractive index.

The forward-modeled total extinction coefficient and total backscatter coefficient are the sum of the molecule and the particle extinction and backscatter coefficients:

$\alpha_{\lambda}(z)=\alpha_{\mathrm{mol}, \lambda}(z)+\alpha_{\mathrm{par}, \lambda}(z)$,

$\beta_{\lambda}(z)=\beta_{\mathrm{mol}, \lambda}(z)+\beta_{\mathrm{par}, \lambda}(z)$,

equivalent to Eqs. (3) and (4).

\subsubsection{Two-way transmission}

The two-way transmission $T_{\lambda}$ is calculated from

$T_{\lambda}(z)=\exp \left(-2 \int_{0}^{z} \alpha_{\lambda}\left(z^{\prime}\right) \mathrm{d} z^{\prime}\right)$.

Within the forward operator, the two-way transmission is discretized by using the models' vertical layers as height increment and vertical resolution.

\subsubsection{Lidar ratio}

Even though the lidar ratio is not measured directly by current ACL systems, the capability of simulating the lidar ratio for given scatterer types and scatterer mixtures offers great potential for sensitivity studies but also for comparison to research lidar systems such as Raman lidar. The forwardmodeled total lidar ratio $S_{\text {lidar }}(z)$ can be calculated from

$S_{\text {lidar }, \lambda}(z)=\frac{\alpha_{\text {par }, \lambda}(z)}{\beta_{\text {par }, \lambda}(z)}$,

where $\alpha_{\text {par, } \lambda}(z)$ and $\beta_{\text {par, } \lambda}(z)$ are the total particle extinction and backscatter coefficients given by Eqs. (15) and (16), respectively. This depends not only on the assumed particle type and shape, but also on the particle size class configuration of the model, i.e., size class number, size class range, and particle size coverage. The forward-modeled lidar ratio thus becomes more representative with a wider particle size spectrum as well as with greater particle size, type, and shape classes output by the dispersion model.

To analyze the lidar ratio sensitivity independent of a models' particle size class and type class configuration, we introduced the pure lidar ratio $S_{\text {lidar,pure. In a molecule-free }}$ volume with monodisperse particles, the particle number per volume $N_{R, p}$, with $R$ as particle radius, cancels, giving

$S_{\text {lidar }, \text { pure }, R, p, \lambda}=\frac{\sigma_{\mathrm{ext}, R, p, \lambda}}{\sigma_{\mathrm{bsc}, R, p, \lambda}}$.

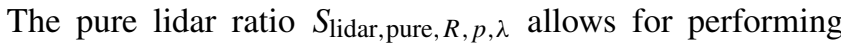
sensitivity studies to analyze influences of the particle shape on the expected lidar ratio values (Sect. 4).

\section{Case study}

\subsection{Description}

The 2010 Eyjafjallajökull eruption was extensively analyzed by scientists from many fields of research, resulting in a substantial knowledge base (see ACP special issue "Atmospheric implications of the volcanic eruptions of Eyjafjallajökull, Iceland 2010”). Ash layers were observed from a large set of measurement instruments, allowing for tracking of the volcanic ash plume over Europe (Gasteiger et al., 2011a; Zakšek et al., 2013; Mona et al., 2012; Dacre et al., 2013; Waquet et al., 2014). Using images from the geostationary instrument SEVIRI (Spinning Enhanced Visible and Infrared Imager) the spatial extent of the ash plumes and their movements could be tracked and compared to the measurement of ground-based instruments (Strohbach, 2015; see Fig. 1). From the synergy of the two measurement systems, layers with strong backscattering measured by ACL systems could be related to clouds or volcanic ash layers.

In terms of dispersion modeling, such a volcanic eruption case has a well-known aerosol source location. This feature renders the Eyjafjallajökull eruption an important case study for aerosol dispersion simulation models and respective validation methods (Matthias et al., 2012).

\subsection{The DWD ACL network}

ACL networks are a valuable data source for analyzing the vertical and horizontal structure of aerosol particles, model verification, and data assimilation. A qualitative analysis of the Eyjafjallajökull ash plume over Germany using observations from 36 ACL systems CHM15k manufactured by Jenoptik (currently known as Lufft) was performed by Flentje et al. (2010a).

We used the NetCDF files with ACL raw data where one file contains the $24 \mathrm{~h}$ measurement of one ACL station. From our analysis of the ACL measurements from 14 to 16 April 2010, we identified six stations where the volcanic ash plume was visible without being tainted by other clouds or hidden by fog layers near the ground. 


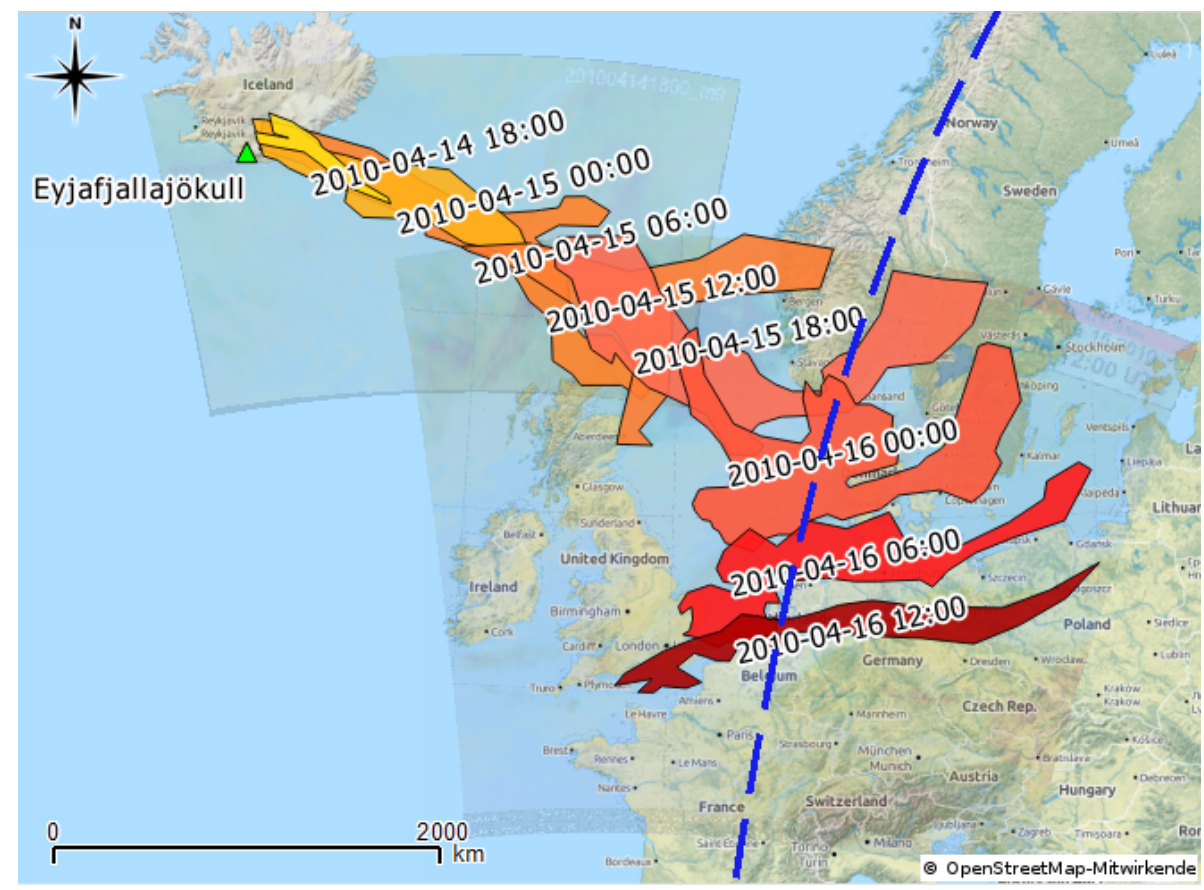

Figure 1. Distribution and transport of volcanic ash over northwest Europe sketched using georeferenced satellite images (Meteosat-9, Dust). After georeferencing, the ash layers were retraced as colored polygons, where the color of the polygons (yellow to red) represent consecutive time steps (Strohbach, 2015). The blue dashed line indicates the flight track of CALIPSO during 17 April 2010 (measurement shown in Fig. 2).

The received photon number per shot is calculated from

$N_{\text {rec }}(z, t)=$ beta_raw $(z, t) \cdot \mathrm{SD}(t)+$ base $(t)$,

where beta_raw is the signal-to-noise measurement product, $\mathrm{SD}$ is noise, and base is a daylight correction provided by the ACL software of this model.

The equation for calculating the attenuated backscatter coefficient from ACL-measured photon counts reads

$\gamma_{\lambda}(z)=\frac{N_{\mathrm{rec}, \lambda}(z, t) z^{2}}{N_{\mathrm{tr}, \lambda} \eta_{\lambda} A_{\mathrm{tel}} O(z) \Delta z}$.

The pulse energy of the diode-pumped laser is $8 \mu \mathrm{J}$ (Flentje et al., 2010b) resulting in an emitted photon number per pulse of about $4.28 \times 10^{13}$. The diameter of the receiving telescope is $100 \mathrm{~mm}$ (Flentje et al., 2010b) which results in $A_{\text {tel }}=78.54 \mathrm{~cm}^{2}$. The vertical resolution $\Delta z$ is $15 \mathrm{~m}$ for the complete profile. The overlap function $O(z)$ was set to 1 which implies that ranges below about $1500 \mathrm{~m}$ cannot be used reliably for comparisons with the forward operator.

Unfortunately, the instruments provided no calibrated measurement data at that time, so a linear calibration factor $\eta^{*}$ is used as replacement for the system efficiency $\eta_{\lambda}$. From a comparison with calibrated attenuated backscatter measurements of CALIOP at $\lambda=1064 \mathrm{~nm}$ (Fig. 2), a calibration factor of $\eta^{*}=0.003$ could be determined; therefore, the CALIOP value of the $1064 \mathrm{~nm}$ calibrated attenuated backscatter coefficient was used at $50.15^{\circ}, 4.81^{\circ}$ at a height of $2 \mathrm{~km}$. As a validation step, the resulting attenuated backscatter coefficient values were compared to Raman lidar measurements of the volcanic ash plume at $\mathrm{Mu}$ nich and Leipzig (Ansmann et al., 2010). The maximum Raman lidar measured backscatter coefficient at $\lambda=1064 \mathrm{~nm}$ was $8 \times 10^{-6} \mathrm{~m}^{-1} \mathrm{sr}^{-1}$ for both Munich and Leipzig and the maximum calculated attenuated backscatter coefficient of the ACL measurement at Deuselbach after calibration is of the same order of magnitude. As most present ACL networks have been extended by automatic calibration capabilities, such pragmatic calibration approaches will not be required in future forward operator studies. It should be noted that it is not only the absolute calibration which is important. Even if the calibration is not perfect, a comparison of lidar and model data permits a thorough comparison of vertical structures such as the thickness and heights of aerosol layers.

As a last step, the high-resolution ACL data was gridded to the model's vertical resolution and to 15 min time steps. This also improved the signal-to-noise ratio of the ACL data.

\subsection{Ash transport simulation of COSMO-ART}

COSMO-ART was set up by DWD in collaboration with Karlsruhe Institute of Technology (KIT) for an ashdispersion simulation of the volcanic emissions during the eruptive phase of Eyjafjallajökull in spring 2010 (Vogel et al., 2014). The model domain was configured to a horizontal grid 


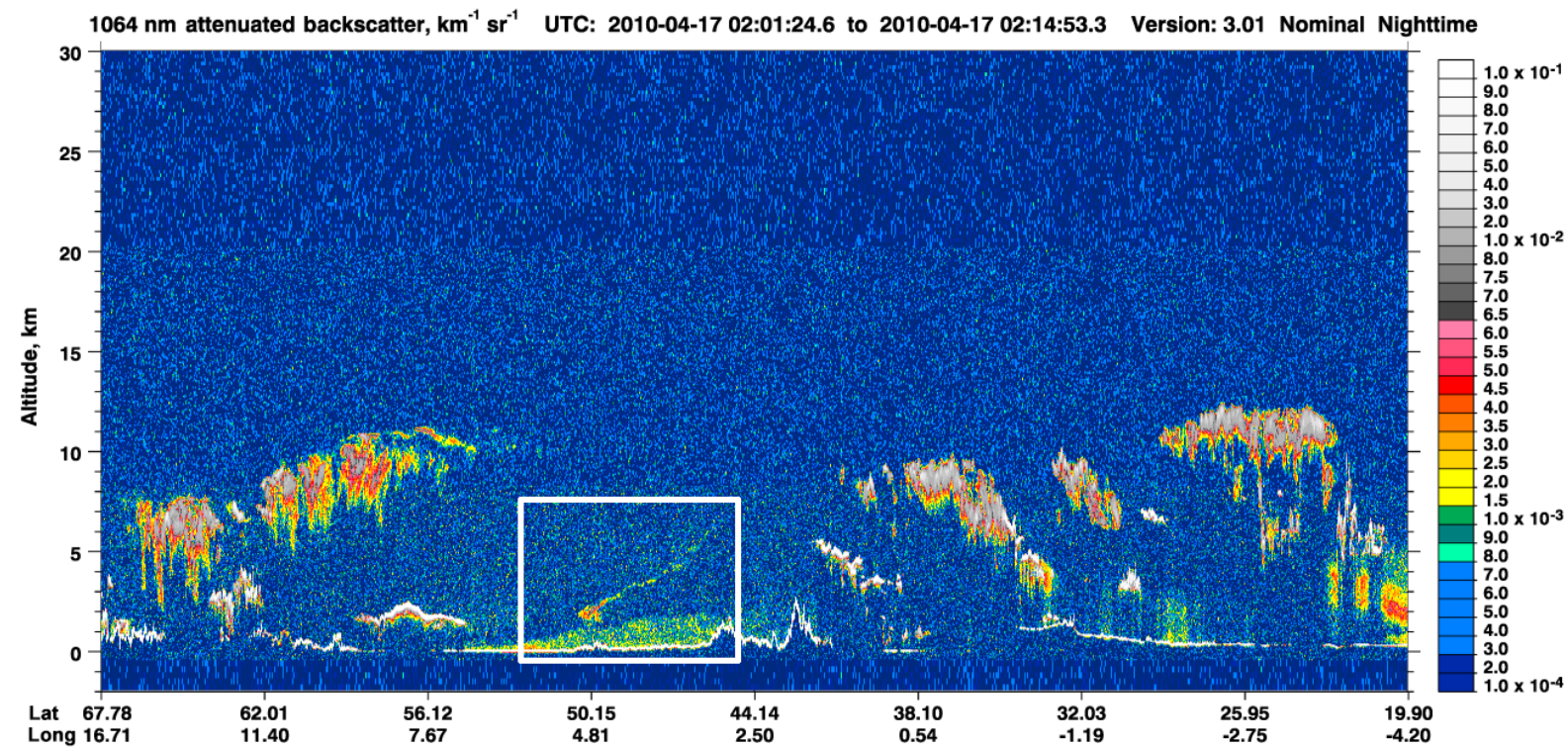

Figure 2. Attenuated backscatter coefficient measurement from CALIOP used to calibrate the ACL measurement during the Eyjafjallajökull eruption phase. The volcanic ash plume is visible around $50.15^{\circ}, 4.81^{\circ}$. As the instrument measures from space, the values of the attenuated backscatter coefficient inside the ash plume is not affected by attenuation due to aerosols in the planetary boundary layer. Image obtained from http://www-calipso.larc.nasa.gov/.

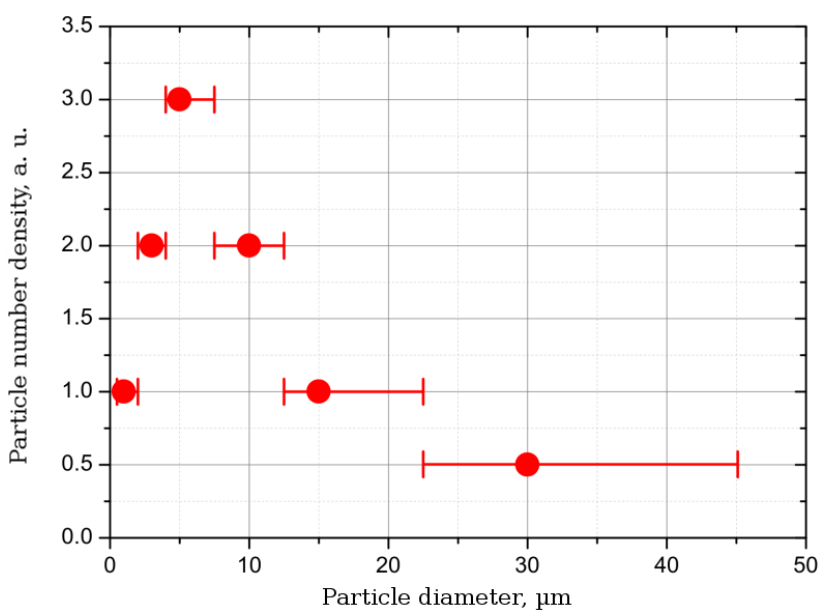

Figure 3. Sketch of the particle size distribution represented by COSMO-ART for the Eyjafjallajökull dispersion simulation (red dots). The red lines with bars indicate the averaging margins that were defined for the calculation of effective optical cross sections.

size of $7 \mathrm{~km}$ and 40 height layers. The height layer thickness was variable, ranging from several meters near the ground to a layer thickness of about $3 \mathrm{~km}$ at $22 \mathrm{~km}$ height above ground level. A more general description of the model run is given by Vogel et al. (2014).

For this study, the $78 \mathrm{~h}$ forecast was used, beginning on 15 April 2010, 00:00 UTC, which includes volcanic ash emission data starting from 14 April 2010, 06:00 UTC. Volcanic ash was represented by six discrete size classes with aerodynamic diameters of $1,3,5,10,15$, and $30 \mu \mathrm{m}$. For each class, a number concentration was predicted by the model. Particles within a class were treated as being identical, i.e., having the same size, shape, and complex index of refraction (monodisperse distribution), so the calculation of effective optical cross sections follows Sect. 2.2.4. The lower and upper size margins $R_{d_{a}}$ and $R_{d_{b}}$ were defined as arithmetic averages of two subsequent size classes. The lower margin of the smallest size class was half its nominal diameter; the upper margin of the largest size class was 1.5 times its nominal diameter. The resulting class ranges are shown in Fig. 3. A list of model variables used for the forward operator is given by Table 1 .

\subsection{Volcanic ash properties}

A detailed analysis of the emitted ash was performed by Schumann et al. (2011) who compared measurements from the DLR Falcon 20 aircraft with data of research lidar systems in Germany. Eyjafjallajökull ash samples were taken in situ, analyzed using a scanning electron microscope, and assigned to matter groups. From the matter components, the complex index of refraction was calculated.

According to Schumann et al. (2011), the real part of the refractive index was between 1.53 and 1.60 at a wavelength of $\lambda=630 \mathrm{~nm}$ and between 1.50 and 1.56 at a wavelength of $\lambda=2000 \mathrm{~nm}$. The respective imaginary part was ranging from -0.001 to $-0.004 i$ at a wavelength of $\lambda=630 \mathrm{~nm}$ and from $-2.0 \times 10^{-6}$ to $-40.0 \times 10^{-6} i$ at a wavelength of $\lambda=$ $2000 \mathrm{~nm}$. 
Table 1. Output variables of COSMO-ART used by the forward operator for the selected case study.

\begin{tabular}{llll}
\hline Variable & Symbol & Description & Unit \\
\hline ASH1 & $N_{1}$ & $\begin{array}{l}\text { Ash number density of } \\
\text { class } 1(1 \mu \mathrm{m})\end{array}$ & $\mathrm{m}^{-3}$ \\
ASH2 & $N_{2}$ & $\begin{array}{l}\text { Ash number density of } \\
\text { class } 2(3 \mu \mathrm{m})\end{array}$ & $\mathrm{m}^{-3}$ \\
ASH3 & $N_{3}$ & $\begin{array}{l}\text { Ash number density of } \\
\text { class } 3(5 \mu \mathrm{m})\end{array}$ & $\mathrm{m}^{-3}$ \\
ASH4 & $N_{4}$ & $\begin{array}{l}\text { Ash number density of } \\
\text { class } 4(10 \mu \mathrm{m})\end{array}$ & $\mathrm{m}^{-3}$ \\
ASH5 & $N_{5}$ & $\begin{array}{l}\text { Ash number density of } \\
\text { class } 5(15 \mu \mathrm{m})\end{array}$ & $\mathrm{m}^{-3}$ \\
ASH6 & $N_{6}$ & $\begin{array}{l}\text { Ash number density of } \\
\text { class } 6(30 \mu \mathrm{m})\end{array}$ & $\mathrm{m}^{-3}$ \\
Pmain & $p$ & $\begin{array}{l}\text { Atmospheric pressure } \\
\text { Atmospheric temperature }\end{array}$ & ${ }^{\circ} \mathrm{CPa}$ \\
\hline
\end{tabular}

Electron microscope images from the same study revealed that the volcanic ash particles were sharp edged with a complex and asymmetric shape. The average asymmetry factor was 1.8 for small particles $(<0.5 \mu \mathrm{m})$ and 2.0 of larger particles (Schumann et al., 2011). Electron microscope measurements of Rocha-Lima et al. (2014) showed that the asymmetry factor of the volcanic ash fine fraction was between 1.2 and 1.8 .

The particle growth due to hygroscopic water coating was quantified to be about 2 to $5 \%$ at a relative humidity of $90 \%$ (Lathem et al., 2011). A growth of 5\% does not change the scattering properties significantly in relation to the size averaging which is performed for monodisperse size classes in the forward operator. But even perfectly known volcanic ash particles will change their constitution while traveling through the atmosphere. It is therefore essential to analyze the maximum uncertainty for applying the forward operator on volcanic ash particles with variable properties, namely particle size, refractive index, and shape.

\section{Sensitivity studies}

The representation of the particles by the model is clearly simplified, so the effect of these simplifications on the scattering of laser light must be determined when applying the forward operator. For a lidar forward model, sensitivities of the backscatter cross section are critical because the received signal intensity is linearly coupled to the backscatter cross section and, consequently, to the attenuated backscatter coefficient.

Prior studies already showed the complexity of nonspherical scattering calculations but there is no universal solution to the problem available. Gasteiger et al. (2011b) used DDA to calculate the scattering properties of complex- shaped particles but the analysis was limited to size parameters up to 20.8 due to the increasing computational time per iteration for increasing particle sizes. The equivalent radius at a wavelength of $1064 \mathrm{~nm}$ would be $3.5 \mu \mathrm{m}$. The computation of a high-resolution multi-dimensional look-up table for up to 10 times larger particles would require an unfeasible amount of time. The study of Kemppinen et al. (2015) focused on individual ellipsoids but assuming an ellipsoidal distribution to represent fractional and sharp-edged particles may lead to less realistic scattering calculation results than assuming spherical scatterers. Consequently, there is no scattering description for Eyjafjallajökull ash predictions of COSMO-ART available. Thus, we decided to treat the volcanic ash as spherical objects with given optical properties (see Sect. 3.4), but we nevertheless analyze and discuss the effect of variable volcanic ash properties in the following.

It must be noted that these studies are required for most aerosol types as most naturally occurring aerosols are not perfectly spherical and even slightly non-spherical ellipsoids may have very different scattering characteristics compared to ideal spheres.

\subsection{Prerequisites}

Look-up tables (LUTs) of Mie efficiencies and optical cross sections have been created to reduce the effort spent on timeconsuming scattering calculations. The look-up tables have three dimensions: size parameter $X_{\lambda}\left(R_{\mathrm{p}}\right)$, real part of the refractive index $m$, and imaginary part of the refractive index $m^{\prime}$.

The reasonable range of size parameters depends on the wavelength of the lidar transmitters and the radius of occurring particles $R_{\mathrm{p}}$. For the ACL systems operating at $\lambda=$ $1064 \mathrm{~nm}$, we get a size parameter range of 1.2 to 142.9 with values of the particle radius of 0.2 to $24.2 \mu \mathrm{m}$; see Eq. (10).

As explained in Sect. 3.4, the refractive index measurements by Schumann et al. (2011) were not performed for the exact wavelength of the ACL systems. Therefore, the reference refractive index and the interval of uncertainty had to be estimated. Schumann et al. (2011) take a refractive index of $1.59-0.004 i$ for their medium " $\mathrm{M}$ " case study and therefore this value is also used as reference for our study. The uncertainty intervals of real and imaginary parts were chosen according to the range of measured values at 630 and $2000 \mathrm{~nm}$, namely a real part range of 1.54 to 1.64 and an imaginary part range of -0.006 to -0.002 . To get an estimate of the overall refractive index sensitivity for such particles, the range of analyzed refractive indices was extended to real parts between 1.49 and 1.69 using increments of 0.001 and to imaginary parts between -0.011 and -0.001 using increments of 0.00005 . Using a radius increment of $0.024 \mu \mathrm{m}$, the total element number of one LUT is $4.0 \times 10^{7}$, and these look-up tables were the base for the refractive index sensitivity study. 

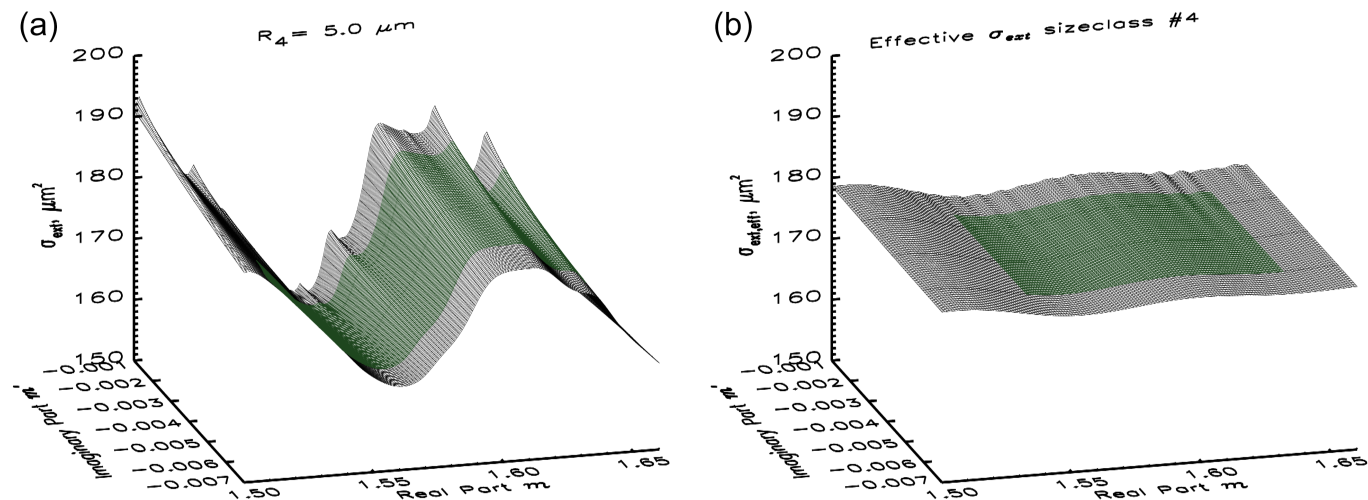

Figure 4. Sensitivity of $\sigma_{\text {ext }}$ to the real and imaginary part of the refractive index for a single particle radius $R_{\mathrm{p}}$ of $5 \mu \mathrm{m}$ (a) and after calculating the effective extinction cross section $\overline{\sigma_{\text {ext }}}$ for size class $4(\mathbf{b})$. The green shaded area is the considered range of real part $m$ and imaginary part $m^{\prime}$ for the uncertainty estimation as explained in Sect. 4.1.
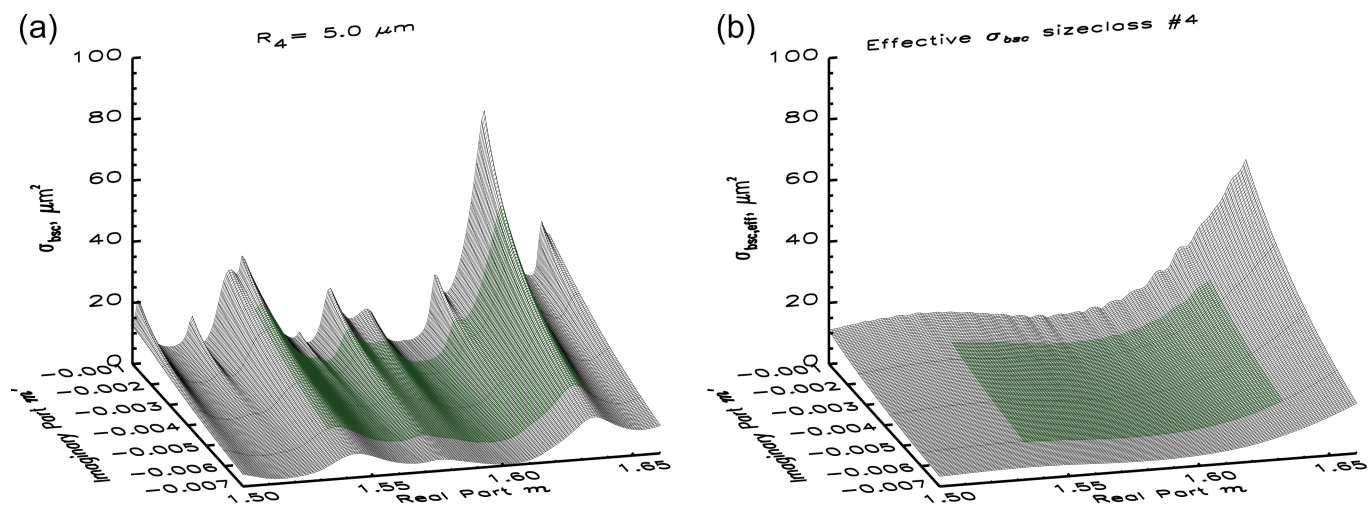

Figure 5. The same as Fig. 4 but for the backscatter cross section $\sigma_{\mathrm{bsc}}(\mathbf{a})$ and the effective backscatter cross section $\overline{\sigma_{\mathrm{bsc}}}(\mathbf{b})$. The backscatter cross section is very sensitive to the refractive index. While the major fraction of backscatter cross section variations can be removed by calculating the effective backscatter cross section, the sensitivity at the extreme end of the defined refractive index remains.

\subsection{Sensitivity to the complex index of refraction}

Extinction cross section $\sigma_{\text {ext }}$, backscatter cross section $\sigma_{\mathrm{bsc}}$, effective extinction cross section $\overline{\sigma_{\text {ext }}}$, and effective backscatter cross section $\overline{\sigma_{\mathrm{bsc}}}$ plotted over real and imaginary parts of the complex index of refraction are shown in Figs. 4 and 5 for a particle radius of $5 \mu \mathrm{m}$ and class 4 as an example. While the extinction cross section $\sigma_{\text {ext }}$ is more sensitive to the real part than to the imaginary part of the refractive index, the backscatter cross section $\sigma_{\mathrm{bsc}}$ is strongly sensitive to both. These sensitivities are strongly reduced for the effective extinction cross section $\overline{\sigma_{\text {ext }}}$ and the effective backscatter cross section $\overline{\sigma_{\text {bsc }}}$.

A measure for the refractive index sensitivity of the effective optical cross sections is given by Fig. 6, which shows the relative errors

$$
\begin{aligned}
& \sigma_{\mathrm{ext}, \mathrm{err}, p}\left(m, m^{\prime}\right)= \\
& \frac{\overline{\sigma_{\mathrm{ext}, p}\left(m, m^{\prime}\right)}-\overline{\sigma_{\mathrm{ext}, p}\left(m^{*}, m^{\prime *}\right)}}{\overline{\sigma_{\mathrm{ext}, p}\left(m^{*}, m^{\prime *}\right)}} \cdot 100 \%,
\end{aligned}
$$

and

$$
\begin{aligned}
& \sigma_{\mathrm{bsc}, \mathrm{err}, p}\left(m, m^{\prime}\right)= \\
& \frac{\overline{\sigma_{\mathrm{bsc}, p}\left(m, m^{\prime}\right)}-\overline{\sigma_{\mathrm{bsc}, p}\left(m^{*}, m^{\prime *}\right)}}{\overline{\sigma_{\mathrm{bsc}, p}\left(m^{*}, m^{\prime *}\right)}} \cdot 100 \% .
\end{aligned}
$$

It is defined as the error of the optical cross sections if the reference refractive index $\left(m^{*}\right.$ and $\left.m^{\prime *}\right)$ was assumed to be true, but real particles have a refractive index of $m$ and $m^{\prime}$. It can be concluded from this analysis that the maximum relative error for the given range of refractive indices is less than $10 \%$ for the extinction cross section but ranges up to $230 \%$ for the backscatter cross section at the outer extremes of the uncertainty range. 

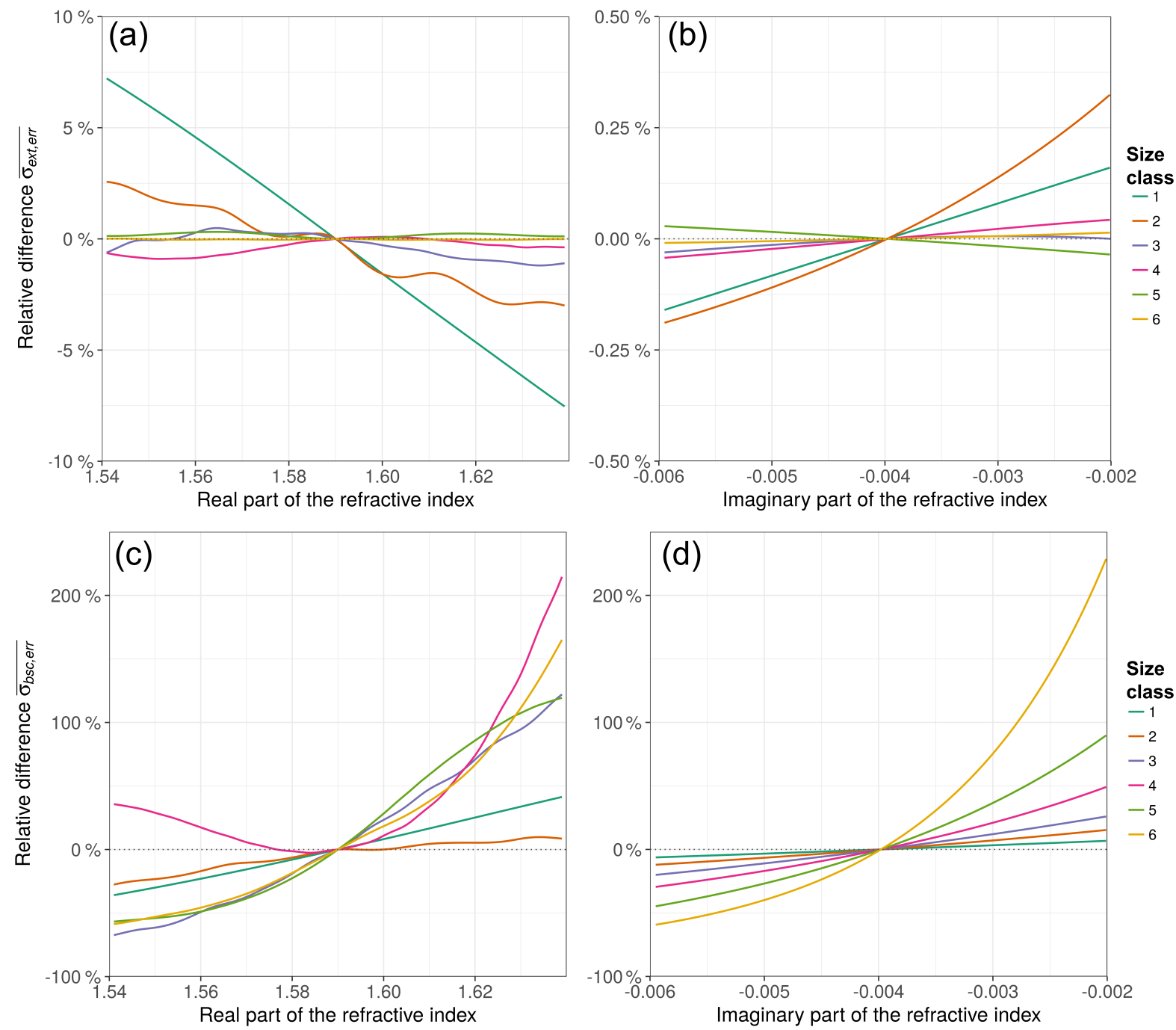

Figure 6. Relative errors of the effective extinction cross section (a, b) and of the effective backscatter cross section (c, d) if the assumed reference refractive index $(1.59-0.004 i)$ varies from the true refractive index. Uncertain real parts of the refractive index (a, c) may lead to errors of $7 \%$ for the effective extinction cross section as well as of $225 \%$ for the effective backscatter cross section. Uncertain imaginary parts of the refractive index $(\mathbf{b}, \mathbf{d})$ may lead to a maximum error of $0.5 \%$ for the effective extinction cross section and of $230 \%$ for the effective backscatter cross section. The maximum error was observed at the outer range of considered refractive indices. Therefore, reducing the considered range of refractive indices reduces the maximum error of the effective extinction and backscatter cross section.

\subsection{T-matrix particle shape sensitivity study}

The T-matrix calculations performed in this study are based on the FORTRAN code for randomly oriented particles, written and provided by Mishchenko and Travis (1998). A detailed description of the method can be found in Mishchenko et al. (2002).

The double-precision version of the T-matrix procedure was modified to perform scattering calculations of multiple particle sizes automatically. In addition, the procedure was extended by calculating and returning the backscatter cross section $\sigma_{\text {bsc }}$ according to Mishchenko et al. (2002), Eq. (9.10). These modifications were tested by comparing the scattering calculation results of the modified code and mie_single for spherical particles and the results were identical.

A list of T-matrix options we used for the particle shape sensitivity study is shown in Table 2 . The most important particle properties are defined by the variables NP and EPS. $\mathrm{NP}$ is the particle type descriptor and has a value of -1 for spheres as well as for ellipsoids. A NP value of -2 is used for cylinders. The variable EPS is an expression for the objects' diameter-to-length ratio: an ellipsoid with EPS $=1$ is a sphere, prolate objects have EPS $<1$, and oblate objects have EPS $>1$. 
Table 2. Settings of the T-matrix procedure for the particle shape sensitivity study. The parameters were kept constant during the study except the particle shape parameters (EPS and NP).

\begin{tabular}{lll}
\hline Variable & Value & Description \\
\hline RAT & 1 & Radius is given as equal-sphere-volume radius \\
NPNAX & 1 & Setting for monodisperse distributions \\
AXMAX & 1 & Setting for monodisperse distributions \\
B & 1 D-1 & Setting for monodisperse distribution \\
NKMAX & -14 & Setting for monodisperse distributions \\
NDISTR & 4 & Setting for monodisperse distributions \\
EPS & $0.5 \ldots 2.0$ & Aspect ratio of the scatterer \\
NP & -1 or -2 & Selects the particle type (spheres NP $=-1$ or cylinders NP $=-2$ ) \\
LAM & $1064.0 \times 10^{-9}$ & Wavelength of incoming light \\
MRR & 1.59 & Real part of the refractive index \\
MRI & -0.004 & Imaginary part of the refractive index \\
NPNA & 19 & Number of random angles \\
\hline
\end{tabular}
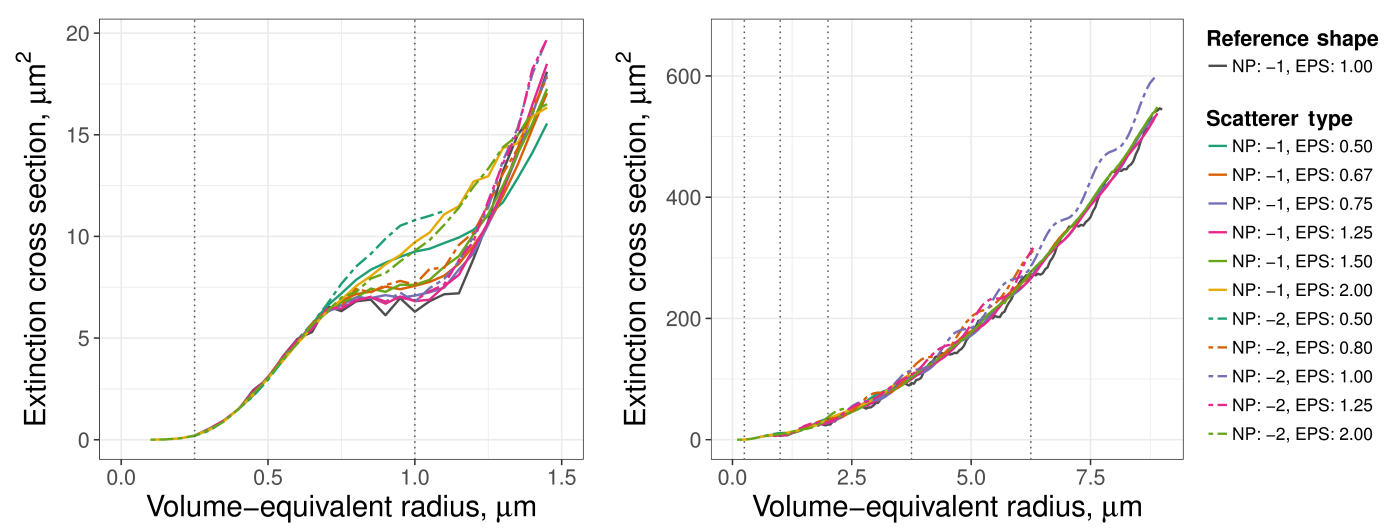

Figure 7. Extinction cross section spectrum for the reference particle (sphere, dark grey line), six types of ellipsoids (EPS $=1$, solid lines), and five types of cylinders (EPS $=-2$, dashed lines) against the particles' equal-volume radius $R_{\mathrm{p}}$ at $\lambda=1064 \mathrm{~nm}$. Vertical dotted lines indicate the size margins of each class. The particle shape effect is negligible for particles with a radius much smaller than the wavelength. Particles which have a radius equal to the wavelength show differences of the extinction cross section depending on their shape. With larger particle sizes, the particle shape effect is negligible for the considered shapes and aspect ratios.

In Figs. 7, 8, and 9, the optical cross sections and the pure lidar ratio of spheres and several aspherical particles are plotted against the equal-volume radius. The aspherical scatterers are six ellipsoids with a diameter-to-length ratio of 0.50 , $0.67,0.75,1.25,1.50$, and 2.00 as well as five types of cylindric particles with a diameter-to-length ratio of $0.50,0.80$, $1.00,1.25$, and 2.00 . Unfortunately, the scattering properties of a highly asymmetric ellipsoid (EPS: 0.50 ) is only available up to an equal-volume radius of $3.75 \mu \mathrm{m}$. For future research activities in this topic, the quadruple precision version of the T-matrix code could be used to extend the upper size range of highly asymmetric particles.

No significant differences between the extinction cross section of spheres and these ellipsoids were observable. The trend is, however, that cylindrically shaped particles have a higher extinction cross section compared to ellipsoids. Spheres have the lowest extinction cross section values over the whole spectrum. Up to a volume-equivalent radius of $0.7 \mu \mathrm{m}$, the shape effect is not noticeable.

Regarding the backscatter cross section, there are significant differences between the backscatter cross section of spheres and particles with other shapes. Obviously, spheres are affected by interference effects which leads to both fluctuating and oscillating values of the backscatter cross section, while the backscatter cross section spectrum of other shapes is only weakly fluctuating. As observed for the extinction cross section, the shape effect becomes pronounced beginning at an equal-volume radius greater than $0.7 \mu \mathrm{m}$. Spherical scatterers have a higher value of the backscatter cross section compared to ellipsoids except for one type of ellipsoid (EPS $=1.25$ ). For cylinders, the backscatter cross section of the analyzed aspect ratios increases monotonically with size. As a result, the backscatter cross section of spheres is lower than that of cylindric particles with the same size if their 

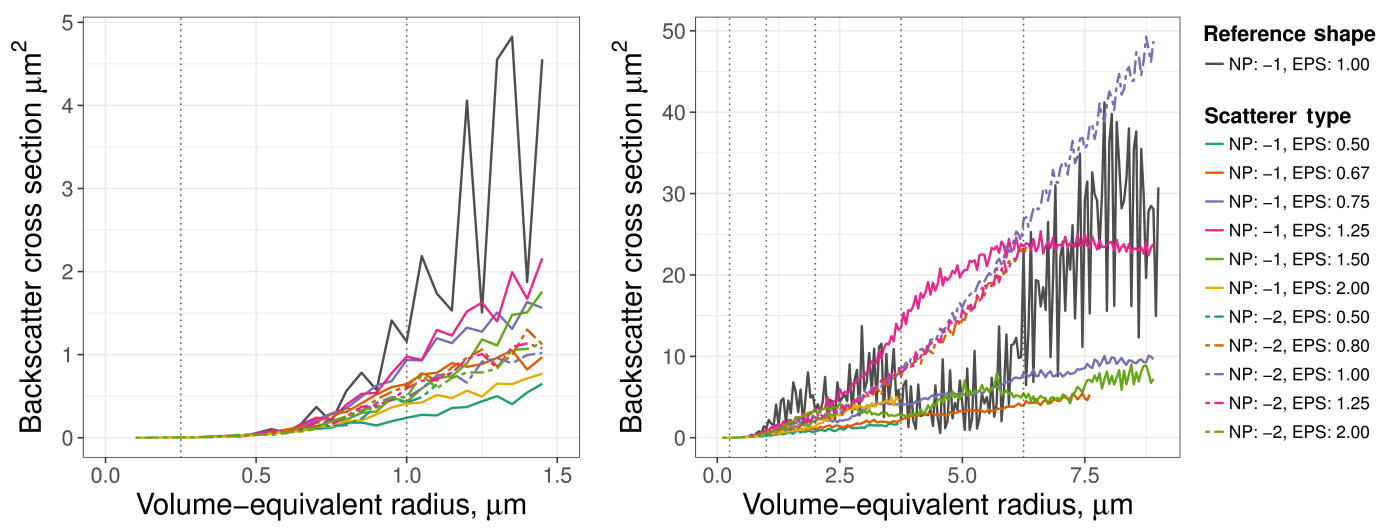

Figure 8. The same as Fig. 7 but for the backscatter cross section. A high particle shape sensitivity of the backscatter cross section can be observed which becomes pronounced for particles with radii greater than $0.5 \lambda$. While the backscatter cross section of ellipsoids increases only weakly with particle size, the backscatter cross section of cylinders increases near exponentially with size. The backscatter cross section spectrum of spheres has larger-scale fluctuations which are due to interference effects. For particle size classes 4 and 5 , the backscatter cross section of spheres is between the values of ellipsoids and cylinders which indicates that a spherical shape is a valid representative for large volcanic ash size classes
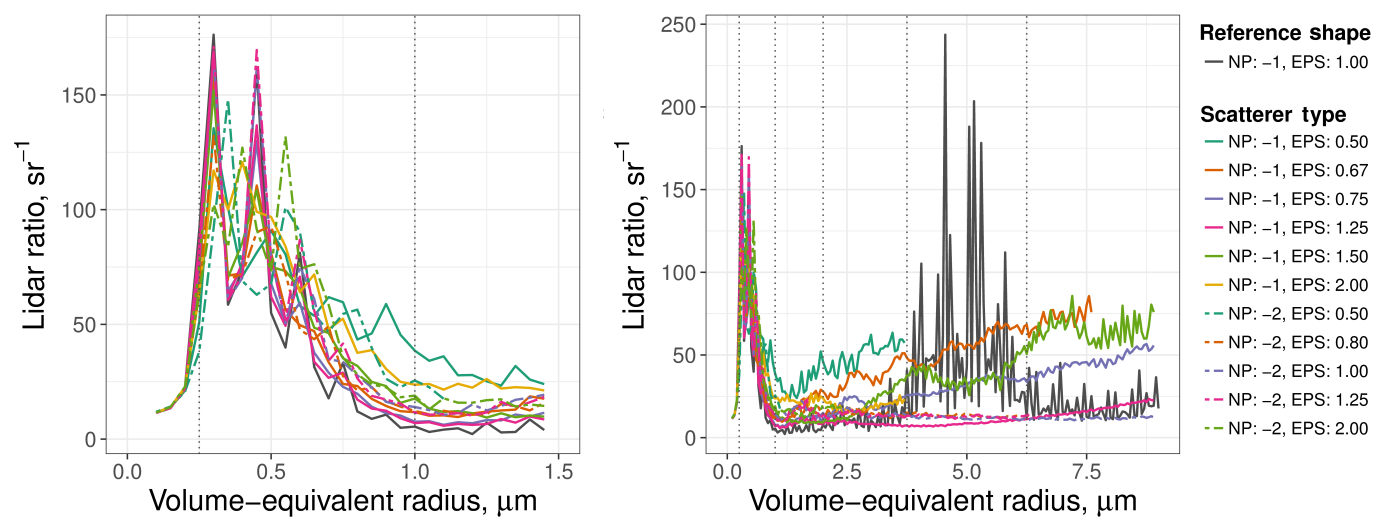

Figure 9. The same as Fig. 7 but for the pure lidar ratio. Similar to the observations for the backscatter cross section (see Fig. 8), the particle shape sensitivity of the pure lidar ratio is negligible for particles smaller than $0.5 \lambda$. For larger particles, the spherical shape tends to have the lowest pure lidar ratio value of all particle shapes (namely for a particle radius between 0.5 and $3.5 \mu \mathrm{m}$ ). Peaks of the pure lidar ratio are observed for spheres with a radius between 4 and $6 \mu \mathrm{m}$ which are due to interference effects. Large ellipsoids tend to have the highest pure lidar ratio values in comparison with other particle shapes; large cylinders have an almost constant value of the pure lidar ratio of about 15 sr.

equal-volume radius is greater than $3.75 \mu \mathrm{m}$ (for the given wavelength of $\lambda=1064 \mathrm{~nm}$ ).

The particle shape effect on the pure lidar ratio is weakly pronounced for small particle sizes (less than $0.75 \mu \mathrm{m}$ ). For larger particles, the pure lidar ratio of spheres is generally lower than that of the other considered shapes which is in agreement with the higher backscatter cross section observed before. For the fourth size class (equal-volume radii around $5 \mu \mathrm{m}$ ), the previously observed interference effects of the spheres' backscatter cross section lead to extreme values of the pure lidar ratio (exceeding a value of $200 \mathrm{sr}$ ). For the size classes 2,3 , and 5 , however, the pure lidar ratio of spheres is lower than that of all other considered particle shapes except for cylinders. This indicates that the assumption of spherical scatterers results in an underestimation of the total lidar ratio if the considered particles are not spherical, and size classes 2,3 , and 5 contribute predominately to the total volcanic ash number density.

A summary of the particle shape sensitivity study is shown in Figs. 10 and 11, giving the relative differences of the effective optical cross sections for different particle shapes. The definition of the relative differences follows Eqs. (24) and (25). The effective extinction cross section of spheres is smaller than the effective extinction cross section of the analyzed asymmetric particles. Regarding the effective backscatter cross section, however, the maximum relative differences are 300 and $-80 \%$. While the small aspherical particles have a smaller effective backscatter cross section 


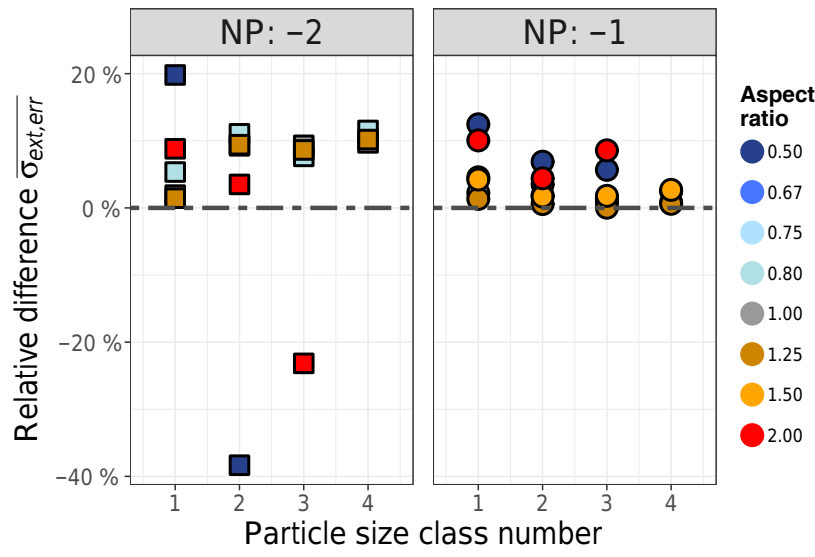

Figure 10. Relative errors of the effective extinction cross section if spherical particles are assumed but real particles have an elliptical (NP: -1$)$ or cylindrical shape (NP: -2 ). Negative values indicate that spherical particles have a larger effective extinction cross section than equal-sized non-spherical particles and vice versa. The maximum relative differences are +11 and $-35 \%$.

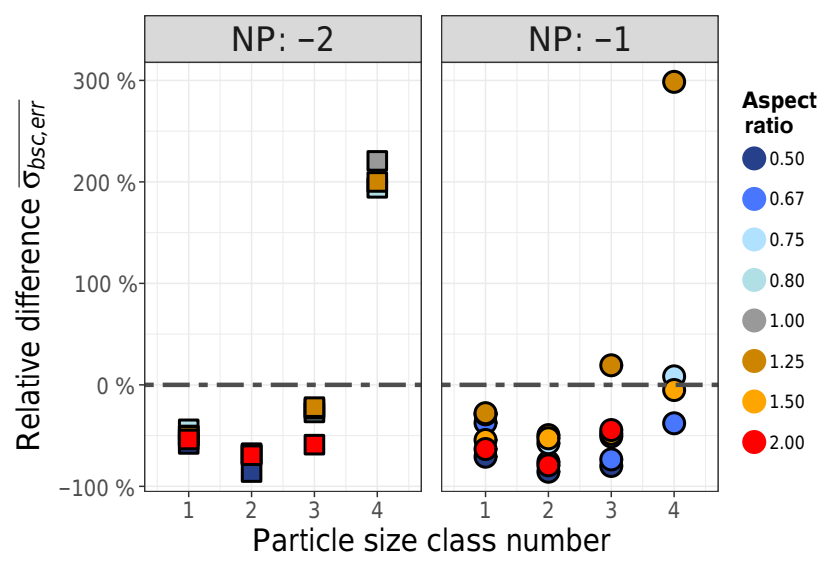

Figure 11. The same as Fig. 10 but for the effective backscatter cross section. The maximum relative difference between the effective backscatter cross section of spherical and non-spherical particles are observed for size class 2 with a relative difference of up to $-80 \%$ (resulting in a difference factor of 5). Even for other size classes, the relative difference is about a factor of 2 when assuming spherical shape for the considered non-spherical particle shapes.

compared to spheres, the effective values of the fourth size class are higher compared to almost all considered aspherical particles. From this analysis, it can be concluded that due to the assumption of sphericity, the backscatter cross section of size classes 1,2, and 3 are overestimated by about a factor of 1.5 to 5 , while the backscatter cross section of the fourth size class is underestimated by a factor of 2 . This allows for quantifying the over- and underestimation of the results for each size class individually, which is not possible for forward operators based on the assumption of a fixed lidar ratio.
Table 3. Effective optical cross sections of atmospheric gas molecules and six volcanic ash size calculated for the ACL wavelength $(\lambda=1064 \mathrm{~nm})$. While the effective extinction cross section increases nearly exponentially with the particle size, the effective backscatter cross section does not even scale linearly with the particle size. Consequently, the ACL-measured attenuated backscatter coefficient is less sensitive to number density variations of size class 6 than those of size class 3 .

\begin{tabular}{lrr}
\hline Scatterer class & $\overline{\sigma_{\text {ext }}}\left(\mathrm{m}^{2}\right)$ & $\overline{\sigma_{\mathrm{bsc}}}\left(\mathrm{m}^{2} \mathrm{sr}^{-1}\right)$ \\
\hline Atmospheric gas & $3.125 \times 10^{-32}$ & $3.680 \times 10^{-33}$ \\
Ash 1 $(1 \mu \mathrm{m})$ & $4.324 \times 10^{-12}$ & $0.328 \times 10^{-12}$ \\
Ash 2 $(3 \mu \mathrm{m})$ & $17.821 \times 10^{-12}$ & $3.843 \times 10^{-12}$ \\
Ash 3 $(5 \mu \mathrm{m})$ & $61.672 \times 10^{-12}$ & $6.200 \times 10^{-12}$ \\
Ash 4 $(10 \mu \mathrm{m})$ & $177.045 \times 10^{-12}$ & $5.365 \times 10^{-12}$ \\
Ash 5 $(15 \mu \mathrm{m})$ & $526.967 \times 10^{-12}$ & $20.442 \times 10^{-12}$ \\
Ash 6 $(30 \mu \mathrm{m})$ & $1937.387 \times 10^{-12}$ & $23.781 \times 10^{-12}$ \\
\hline
\end{tabular}

\section{Comparison of model output with observations}

\subsection{Scattering properties of volcanic ash used within the forward operator}

A list of effective extinction cross section and effective backscatter cross section values for atmospheric gas molecules and for the six volcanic ash size classes is shown in Table 3.

\subsection{Output variables of the forward operator}

Using the forward operator allows for plotting each variable of the lidar simulation for analytic purposes (see Fig. 12). These plots of forward-operator output variables are representing the major characteristics of the variables: strong extinction and strong backscattering are usually related. Time and height intervals where only molecules exist lead to low values of the extinction coefficient and backscatter coefficient. Due to the decrease in the atmospheric gas number density with height, both extinction and backscatter coefficient decrease with height in an aerosol-free atmosphere. The two-way transmission decreases with height (see Eq. 19).

In comparison with Raman lidar measurements, both the maximum measured extinction coefficient of $4.0 \times$ $10^{-4} \mathrm{~m}^{-1}$ and the maximum backscatter coefficient of $8.0 \times$ $10^{-6} \mathrm{~m}^{-1} \mathrm{sr}^{-1}$ inside the volcanic ash plume (Ansmann et al., 2010) are nearly equal to the respective maximum values output by the forward operator at Deuselbach station: the Raman lidar measured values are slightly lower than the values output by the forward operator which could be due to assumptions related to the forward operator or due to an overestimation of the COSMO-ART-predicted aerosol number density.

From output of the forward operator, the relative contribution to the total signal and total mass density can be analyzed 

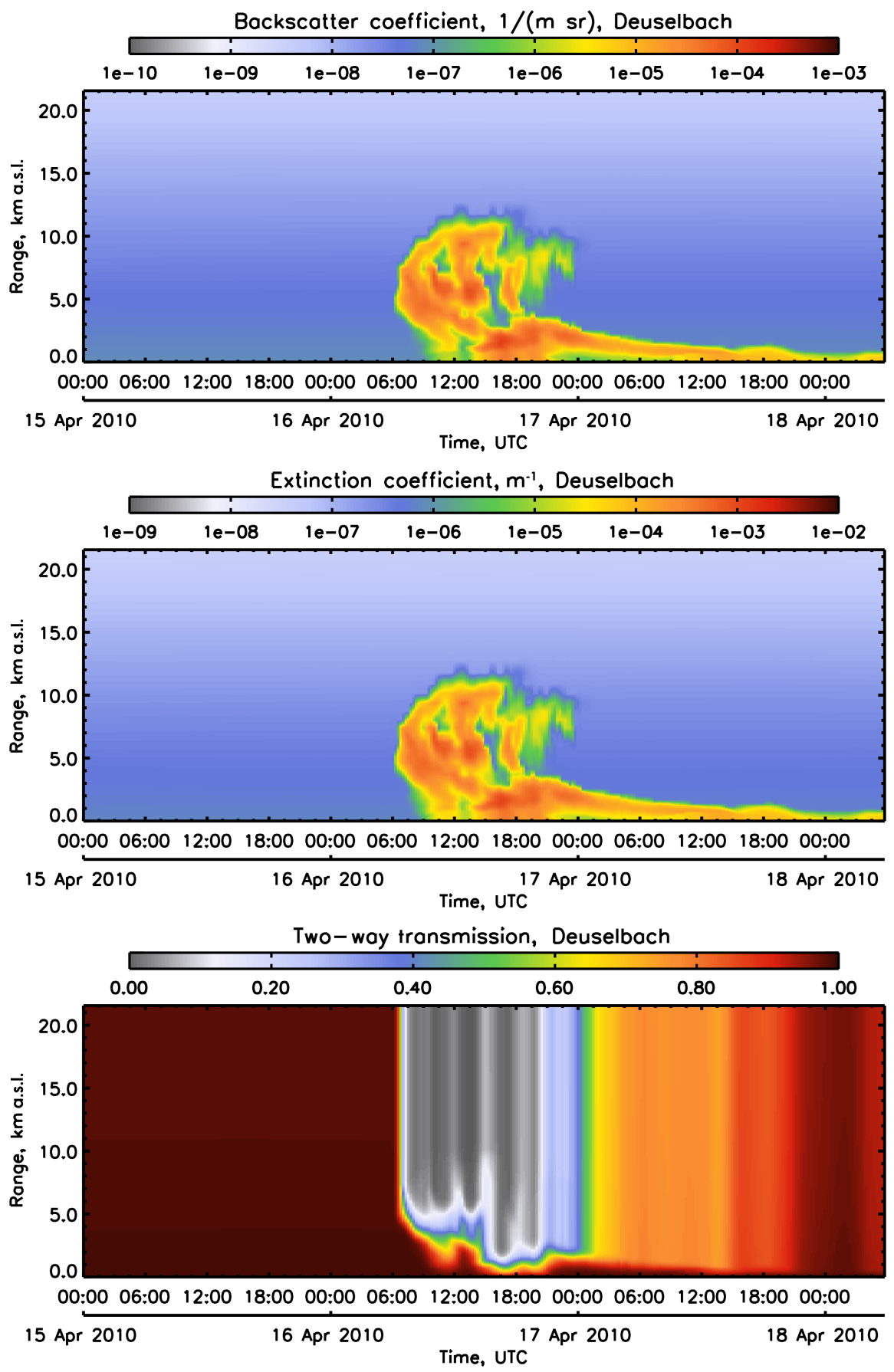

Figure 12. Time-height cross section of total backscatter coefficient, extinction coefficient, and two-way transmission, calculated by the forward model based on COSMO-ART output at Deuselbach station (western Germany). The vertical coordinates are given in kilometers above sea level (a.s.l.). The forward model used temperature, pressure, and volcanic ash particle data (no clouds, rain, fog, background aerosol, or other scattering objects). The two-way transmission is near 1 over clean-air conditions. Above ash layers, however, the two-way transmission has a value of only $5 \%$.

for each size class of COSMO-ART, and total lidar ratio can also be calculated. This was done, for example, at two timeheight coordinates: the first coordinate points to model output from a coordinate inside the volcanic ash layer (Table 4).
Coordinate 2 points to a coordinate where the major fraction of the particle mass is contributed by size classes 4 and 6 (see Table 5). 
Table 4. Point-data extraction of COMSO-ART output at the Deuselbach ACL station; coordinate 1 is on 16 April 2010, 18:00 UTC, at a height of $1.9 \mathrm{~km}$ a.s.l. The individual backscatter coefficient $\beta_{\text {par, } d, \lambda}$, the contribution to the total backscatter coefficient $\sum \beta_{\mathrm{par}, d, \lambda}$, the individual mass density $\rho_{d}$, and the contribution to the total mass density $\sum \rho_{d}$ were calculated based on the model-predicted particle number density $N_{d}$ of each size class d at this coordinate. Ash particles were calculated using a volumetric mass density of $2500 \mathrm{~kg} \mathrm{~m}^{-3}$. A non-linear relationship between the relative contribution to the total backscatter coefficient and the relative contribution to the transported mass of an ash size class can be observed: while the first three classes contribute $95 \%$ of the total backscatter coefficient, they carry only $78 \%$ of the volcanic ash mass. This dependency on the laser wavelength can be seen as an advantage for multi-wavelength lidar systems.

\begin{tabular}{rrrrrr}
\hline$d$ & $N_{d}$ & $\beta_{\mathrm{par}, d, \lambda}$ & $\begin{array}{c}\beta_{\mathrm{par}, d, \lambda} \\
\sum \beta_{\mathrm{par}, d, \lambda}\end{array}$ & $\rho_{d}$ & $\rho_{d}$ \\
- & $\mathrm{m}^{-3}$ & $\mathrm{~m}^{-1} \mathrm{sr}^{-1}$ & - & $\mathrm{kg} \mathrm{m}^{-3}$ & - \\
\hline 1 & 43653522 & $1.4 \times 10^{-5}$ & $22.3 \%$ & $0.57 \times 10^{-7}$ & $3.3 \%$ \\
2 & 7044794 & $2.7 \times 10^{-5}$ & $41.9 \%$ & $2.49 \times 10^{-7}$ & $14.2 \%$ \\
3 & 3194338 & $2.0 \times 10^{-6}$ & $30.7 \%$ & $5.23 \times 10^{-7}$ & $29.8 \%$ \\
4 & 462402 & $2.5 \times 10^{-6}$ & $3.8 \%$ & $6.05 \times 10^{-7}$ & $34.5 \%$ \\
5 & 37161 & $7 . \times 10^{-7}$ & $1.2 \%$ & $1.64 \times 10^{-7}$ & $9.3 \%$ \\
6 & 4474 & $1.1 \times 10^{-7}$ & $0.2 \%$ & $1.58 \times 10^{-7}$ & $9.0 \%$ \\
\hline & & & & &
\end{tabular}

Table 5. The same as Table 4 but for coordinate 2 on 16 April 2010, 09:00 UTC, at a height of $1.5 \mathrm{~km}$ a.s.l. Even if class 4 carries only $27 \%$ of the mass, it contributes $67 \%$ of the total backscatter coefficient. The inverse situation can be observed for the size class 6 , which holds $73 \%$ of the mass but contributes only $30 \%$ of the backscatter coefficient at this coordinate.

\begin{tabular}{rrrrrr}
\hline$d$ & $N_{d}$ & $\beta_{\mathrm{par}, d, \lambda}$ & $\begin{array}{c}\beta_{\mathrm{par}, d, \lambda} \\
\sum \beta_{\mathrm{par}, d, \lambda}\end{array}$ & $\rho_{d}$ & \multicolumn{1}{c}{$\rho_{d}$} \\
& $\mathrm{~m}^{-3}$ & $\mathrm{~m}^{-1} \mathrm{sr}^{-1}$ & - & $\mathrm{kg} \mathrm{m}^{-3}$ & - \\
\hline 1 & 93.0 & $30.7 \times 10^{-12}$ & $0.2 \%$ & $0.01 \times 10^{-9}$ & $0.1 \%$ \\
2 & 97.0 & $372.5 \times 10^{-12}$ & $2.8 \%$ & $0.01 \times 10^{-9}$ & $0.1 \%$ \\
3 & 1.0 & $6.2 \times 10^{-12}$ & $0.1 \%$ & $0.01 \times 10^{-9}$ & $0.1 \%$ \\
4 & 1700.0 & $9129.0 \times 10^{-12}$ & $67.3 \%$ & $2.23 \times 10^{-9}$ & $27.1 \%$ \\
5 & 0.5 & $10.2 \times 10^{-12}$ & $0.1 \%$ & $0.01 \times 10^{-9}$ & $0.1 \%$ \\
6 & 169.0 & $4018.8 \times 10^{-12}$ & $29.6 \%$ & $5.97 \times 10^{-9}$ & $72.8 \%$ \\
\hline
\end{tabular}

Regarding coordinate 1 , the total backscatter coefficient is dominated by ash size classes 1,2 , and 3 , while the signal contribution of classes 4,5 , and 6 is less than $5 \%$ in total. The mass contribution is dominated by classes 3 and 4 while classes 2,5 , and 6 contribute $10 \%$ of the total mass density. The total lidar ratio is $9.63 \mathrm{sr}$. Regarding coordinate 2, class 4 contributes about $68 \%$ and class 6 about $30 \%$ to the total backscatter coefficient. The mass contribution in coordinate 2 is also dominated by classes 4 and 6 but, in contrast to the backscatter coefficient, class 6 has a higher contribution to the total mass density than class 4 . The total lidar ratio at this coordinate with predominately large particles is $46.53 \mathrm{sr}$.
General conclusions from this analysis about the relationship between backscattering and mass, depending on particle size and wavelength, require further investigation. For an application of the forward operator in this study, however, there are two aspects to be mentioned: first, the backscattering intensity inside the volcanic ash layer (coordinate 1) is predominantly dependent on classes 1,2, and 3, whose backscatter cross sections are also overestimated by the forward operator due to the assumption of sphericity (see Fig. 11). The real values of the total lidar ratio may be a factor of 2-3 greater in certain cases (see Sect. 4.3). Second, the larger particles of classes 4,5 , and 6 carry a large portion of the mass but contribute only weakly to the total signal. This may be important information for the selection of future ACL networks. Prior studies confirm that even the systems operating at a relatively long wavelength of $1064 \mathrm{~nm}$ have a reduced sensitivity for giant and ultra-giant particles (Madonna et al., 2013).

\subsection{Qualitative comparison}

A comparison of ACL measurement and COSMO-ART simulation with an applied forward operator at the Deuselbach ACL station in western Germany is shown in Fig. 13. The ash layer was clearly visible in the measured profiles without being affected by low-level or high-level clouds. Due to the inevitable instrumental noise and subsequent background subtraction, some data points become negative which is just a statistical effect but causes missing data in the log-scale plots. Volcanic ash plumes are clearly visible in both plots. Looking at the forward operator result, the ash layer begins to cross the ACL station between 06:00 and 12:00 UTC on 16 April 2010. The layer height decreases with time and partially entrains into the planetary boundary layer, where it persists even through the end of 17 April 2010. As both model and forward operator only represent volcanic ash and air molecules, the ash layers can be tracked within the planetary boundary layer. This is not possible using ACL measurements alone as the volcanic ash signal is tainted by other aerosol types. It is, however, difficult to determine unambiguously which ash layer structure observed by the ACL instrument can be related to corresponding structures simulated by the model. Regarding the thin volcanic ash layer which is measured by the ACL instrument at a height between 7 and $9 \mathrm{~km}$ a.s.1. on 16 April 2010, around 06:00 UTC, this feature could be equivalent to the model prediction of ash at a height of $6 \mathrm{~km}$ a.s.l. at 07:00 UTC. In this case, the model would have performed a rather precise prediction with only $1 \mathrm{~h}$ time lag and a $2 \mathrm{~km}$ vertical shift. But it is also possible that the predicted ash entrainment over the ACL station is equivalent to the ash-indicating ACL signals at around 12:00 UTC. In this case, the model prediction would be wrong by a time lag of about $6 \mathrm{~h}$, which is insufficient for time-critical applications.

The qualitative comparison is currently limited to coordinates where the major fraction of scatterers are represented 


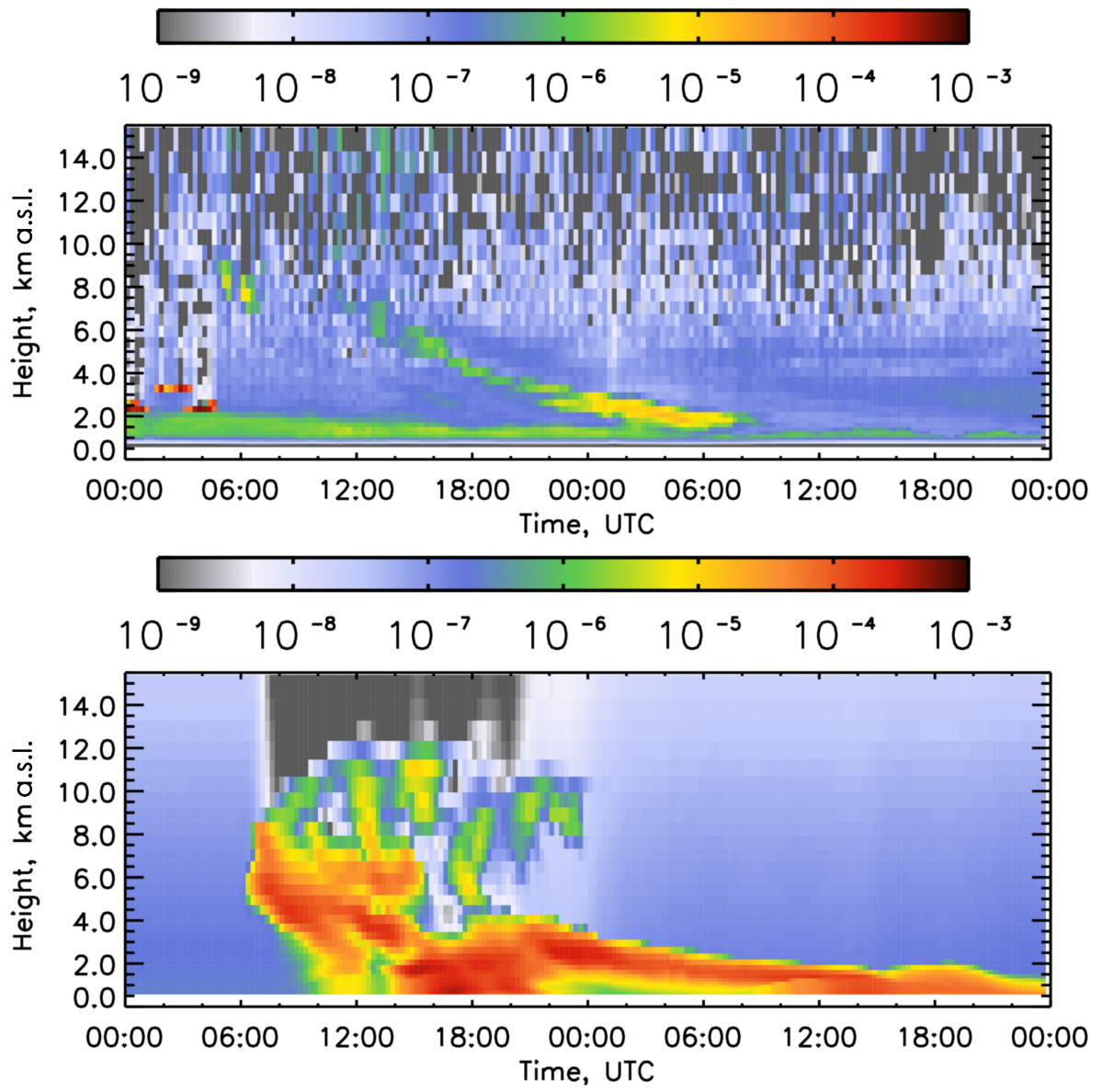

Figure 13. Attenuated backscatter coefficient of ceilometer (top) and forward model (bottom) at Deuselbach station in Germany from 16 April 2010, 00:00 UTC, to 17 April 2010, 24:00 UTC, given in units of $\mathrm{m}^{-1} \mathrm{sr}^{-1}$. The ACL measurements in heights above $8 \mathrm{~km}$ a.s.l. are strongly affected by noise which limits the comparability of both data sets. A comparison of samples near the ground is limited by the missing overlap correction of ACL data and the lack of background aerosol prediction data. The ash layers in heights between 2 and $8 \mathrm{~km}$ a.s.l. allow for identifying similar and non-similar structures of measurement and forward-modeled COSMO-ART predictions of the Eyjafjallajökull ash. The maximum value of the (non-calibrated) ACL-measured attenuated backscatter coefficient is by about 1 order of magnitude lower than the attenuated backscatter coefficient from COSMO-ART prediction with BaLiFOp applied.

by both model and forward operator. There are, however, some scatterer fractions still missing in the present model runs for a comprehensive comparison: aerosol types other than volcanic ash such as anthropogenic emissions, mineral dust, soot, and pollen are not included, which leads to differences, especially in the planetary boundary layer. It is hard to predict yet whether the strong ACL signal in the planetary boundary layer is related to background aerosol extinction or errors of the COSMO-ART prediction. To further investigate this problem, future studies with several types of aerosols incorporated into the model are required.

\subsection{Quantitative comparison}

A major purpose of the backscatter lidar forward operator is also performing quantitative comparisons of measurement and model output data. Unfortunately, such a comparison is of limited validity in this case study due to the unknown ACL calibration as noted in Sect. 3.2.

Outside the volcanic ash layer, the forward operator returns an attenuated backscatter coefficient value of $1 \times$ $10^{-7} \mathrm{~m}^{-1} \mathrm{sr}^{-1}$, which is equal to the value of the ACL instrument after calibration. This would be expected as both temperature and pressure are rather precisely determinable and the scattering properties of air are represented by the empirical equations which are used for the forward operator. Thus, the selected calibration factor seems to be valid for this scenario.

Regarding the attenuated backscatter coefficient inside the ash layer, however, the forward operator returns stronger signals inside the ash plume as well as a lower transmission behind the ash plume compared to the ACL measurement. The maximum value of the attenuated backscatter coefficient returned by the forward operator (about $6.0 \times 10^{-4} \mathrm{~m}^{-1} \mathrm{sr}^{-1}$ ) 
is 20 times higher than the maximum value reported by the ACL (about $3.0 \times 10^{-5} \mathrm{~m}^{-1} \mathrm{sr}^{-1}$ ). Also, the forwardmodeled attenuated backscatter coefficient shows strong attenuation due to the volcanic ash layer at $12 \mathrm{~km}$ a.s.l.: the attenuated backscatter coefficient is by about a factor of 10 15 lower than at the same heights above clean-air conditions. Both findings indicate an overestimation of the modelpredicted volcanic ash number density. However, an overestimation of the ash concentration and preferring false alarms over misses are reasonable strategies for determining the hazardousness of volcanic ash particles using ash dispersion models.

\section{Conclusions}

A backscatter lidar model capable of calculating both the extinction and backscatter coefficients was introduced. Detailed studies concerning the scattering properties of particles and molecules were performed. Instead of assuming a lidar ratio for given particles, this forward operator allows for calculating the scattering properties even for mixtures of different particle types. Data of a COSMO-ART ash-dispersion simulation for the Eyjafjallajökull eruption in 2010 were used to run the forward operator and perform both qualitative and quantitative comparisons between the output of the forward operator and measurement data of an automated ceilometer lidar (ACL) system. A major challenge for setting up the forward operator for a given scenario is the calculation of the effective extinction cross section $\overline{\sigma_{\text {ext }, R_{d}, k, \lambda}}$ and the effective differential backscatter cross section $\overline{\sigma_{\mathrm{bsc}, R_{d}, k, \lambda}}$ of all modelrepresented particle size and type classes.

The atmospheric gas mixture was treated as a uniform mixture of atmospheric gas and empirical scattering formulas were used to calculate its optical cross sections for the ACL laser wavelength. From the model-predicted values of temperature and pressure, the molecule number density and finally the molecule extinction and backscatter coefficients were calculated.

For particle scattering, the ranges of particle sizes were selected according to the volcanic ash classes used by COSMO-ART (six monodisperse classes with diameters of $1,3,5,10,15$, and $30 \mu \mathrm{m})$. The range of considered refractive indices were adapted according to in situ measurements of Schumann et al. (2011).

Due to uncertain refractive indices and shapes of the volcanic ash, sensitivity studies have been performed to analyze the impact of different particle types and shapes on the effective extinction and backscatter cross section and the pure lidar ratio. While the extinction cross section was only weakly sensitive to variable refractive indices and particle shapes, the backscatter cross section was strongly sensitive to both. However, the sensitivities reduce significantly when applying size-averaging algorithms. After averaging, the relative uncertainty of the effective backscatter cross section is up to $280 \%$ within the defined range of refractive indices. This study also indicates the dependency of the forward operator on precise information about the particle's refractive index.

From the findings of Rocha-Lima et al. (2014), the average aspect ratio of volcanic ash is known but there is no information about a distribution function of particle shapes and real volcanic ash particles have an infinite variety of particle shapes. Consequently, the spherical shape was used as reference even if the real volcanic ash particles are known to be fractal and complex shaped. Within a particle shape sensitivity study, the impact of the particle shape on extinction and backscatter cross sections was analyzed for 11 particle shapes (6 types of ellipsoids and 5 types of cylinders). The backscatter cross section spectrum of cylinders was different than the spectrum of ellipsoids and spheres. Sensitivity studies as presented here are mandatory for stepwise improving the knowledge of scattering calculations related to lidar forward models. More detailed studies of scattering at nonspherical particles are thus mandatory to better represent the particle shape in the calculation of the effective backscatter cross section.

In the literature, we find measured lidar ratio values for volcanic ash between $40 \mathrm{sr}$ and greater than $100 \mathrm{sr}$ (Kokkalis et al., 2013; Mortier et al., 2013). This range of values could be observed within sensitivity studies of the pure lidar ratio (Sect. 4.3). From our analysis, the assumption of spherical particles results in a general underestimation of the lidar ratio except for size classes 1 and 4. Comparing the pure lidar ratio values of the first two size classes with the values reported by Gasteiger et al. (2011b), values of less than $20 \mathrm{sr}$ seem to be plausible for these size parameters. The authors found a pure lidar ratio between 5 and $20 \mathrm{sr}$ at size parameters between 5 and 15 (equivalent particle diameter at $\lambda=1064 \mathrm{~nm}$ is 1.6 and $4.8 \mu \mathrm{m}$, respectively) even for irregularly shaped objects. The pure lidar ratio values output by the forward operator are thus realistic.

The total lidar ratio calculated from COMSO-ART output at sample coordinates 1 and 2 resulted in values of 9.63 and $46.53 \mathrm{sr}$, respectively, which is - for the first coordinate - lower than the lidar ratio values of the Eyjafjallajökull ash plume measured by Raman lidar above Munich and Leipzig. From our analysis of the pure lidar ratio, we found an underestimation of the calculated lidar ratio for some size classes due to the assumption of spherical volcanic ash particles. However, the particle size class configuration of the model could also have a huge effect on the calculated lidar ratio values due to the ash size coverage and ash size class configuration. Therefore, the forward-modeled total lidar ratio in this scenario is not expected to exactly match the lidar ratio derived from measurements. Further investigation on this topic is required to optimize the particle size class configuration of models using monodisperse size classes and the representation of non-spherical particles in the forward operator in order to obtain a better representation of the total lidar ratio. 
A time-height cross section comparison of ACL measurement and forward-modeled COSMO-ART output was shown. Similar structures were observed but some features were found at different times and heights. At the Deuselbach ACL station, some ash layer features were predicted quite precisely by the model, for example the time of arrival of the ash plume at about 06:00 UTC but vertically shifted by about $1.5 \mathrm{~km}$. The ash plume intersection with the planetary boundary layer on 17 April 2010 at 03:00 UTC was simulated about $9 \mathrm{~h}$ too early on 16 April 2010 at 18:00 UTC. Fine structures of the ash layer were only observable in the simulation but not in the ACL data due to noise. Furthermore, the contribution of individual classes to the total backscatter coefficient and to the total mass density for two sample cases were analyzed.

The missing calibration coefficients of the ACL system required the definition of a calibration constant $\eta^{*}$ and to estimate its value comparing the ACL data with calibrated measurements at the same wavelength. Within quantitative comparisons between ACL measurements and the forward operator output, the molecule signal of ACL and forward operator output were of the same order of magnitude which suggests that the selected calibration factor was reasonable.

A comparison of the measured and forward-modeled volcanic ash-attenuated backscatter coefficient inside the volcanic ash plume led to the conclusion that the modelpredicted ash concentration was too high which could potentially be resolved by reducing the model-predicted ash concentration manually by a given factor until the forwardmodeled COSMO-ART predictions and ACL measurements are quantitatively similar. Such a reduction could be part of a simple particle data assimilation system helping to calibrate particle dispersion simulations before in situ measurements are available - assuming that the particles optical properties are known. It is therefore required to develop methods in the future which allow for fast determination of an aerosol type's refractive index range, shape and aspect ratio.

As aerosol dispersion processes are directly coupled to vertical and horizontal movements in the atmosphere, a comparison of forward-modeled and measured backscatter lidar profiles offers great potential for validating and improving the dynamic and thermodynamic components of an atmospheric chemistry model. For a model with variational data assimilation methods, the data assimilation system would select the prediction variation which best fits the atmospheric state provided by lidar measurements, resulting in continuous adaptation of the model prediction to the real-world situation.

The absolute values reported by the Raman lidar systems at a wavelength of $1064 \mathrm{~nm}$ agreed within the measurement uncertainties and expected natural differences in the sampled air mass with the results of the forward operator; see Sect. 5.2. This is quite remarkable given the large uncertainties of the ash data in the model (assumed emission rate of the volcano, atmospheric dynamics, dynamic of the modeled ash plume in the atmosphere including sedimentation) and that there is no data assimilation regarding aerosol data at all yet. Further studies could focus on a comparison of forward-modeled lidar profiles and measurements from Raman or multi-wavelength lidar. In this context, the upcoming ESA satellite sensor EarthCARE with its HSRL is certainly of great interest.

There are, however, some error sources remaining: first, there are only molecules and the six volcanic ash classes represented while background aerosol is missing completely. Second, the ACL calibration is of limited precision. Third, the contribution to the attenuated backscatter coefficient of ash size classes 4, 5, and 6 is relatively low even though these classes carry a large portion of the mass. This relationship depends on the ACL's wavelength. In our case of a wavelength of $1064 \mathrm{~nm}$, the sensitivity is highest for particles with a diameter smaller than about $10 \mu \mathrm{m}$. Such results strengthen the importance of the joint use of observations and model output in combination with data assimilation in order to get a reliable description of the atmospheric state with respect to aerosol distributions and properties.

In conclusion, further investigation in scattering calculations of non-spherical particles is recommended to get more realistic optical cross sections for the forward operator. A decrease in uncertainties related to the forward operator can be achieved by refractive index measurements at the exact ACL wavelength. Refractive index measurements are a basic aspect of the forward operator as the optical cross sections can only be calculated if the aerosols' refractive index is known precisely. The model - and consequently the forward operator - must represent more aerosol types, especially background aerosols, mineral dust, sea salt, and soot, as missing extinction near the ground may cause the forward operator to overestimate the attenuated backscatter coefficient value from layers behind. Additionally, qualitatively more scatterer size classes are required to also represent the fine fraction and very large particles in the atmosphere. One approach for a better representation of the natural size spectrum of aerosols is the use of continuous number-size distributions which are aggregated from multiple distribution functions ("modal" approach). This already includes the size averaging which is necessary for monodisperse size distributions. Furthermore, the model delivers exact information about the outer margins, i.e., the number density of the fine and the extreme coarse fraction which is currently not reproduced by model and forward operator in the selected case study.

As many ACL devices are operating proprietary firmware, the manufacturers have to be sensitized to data quality and reproducible measurement calibration. Therefore, it is required that calibration is performed automatically and transparently. In future lidar measurement networks, the number of HSRL systems and Raman lidar systems could potentially increase and allow for the assimilation of extinction coefficient and backscatter coefficient directly. Activities are ongoing to collect, homogenize, and distribute observations within an international framework using present automated lidar systems. 
Observation projects such as EARLINET (Pappalardo et al., 2014) and E-PROFILE (EUMETNET Profiling Programme) also focus on data quality improvements to meet the requirements of numerical weather prediction (NWP). In the spirit of these international activities, the creation of a central database for aerosol scattering properties and forward operators would be desirable. Such a database can increase the development rate, flexibility, and applicability of current and future lidar forward operator implementations. Our operator is the basis also for other, more sophisticated operators and probably the best for backscatter lidar. The methodology and analysis presented here will be helpful for stepwise improving our knowledge in how to deal with the important task of aerosol monitoring, modeling, and data assimilation in the future.

The uncertainties in both modeling and measurements will require sophisticated data assimilation algorithms not only for typical atmospheric variables but also for aerosol optical properties. Also a very good first guess of model simulations with respect to aerosol particles will be necessary so that more sources, types, and sinks can be included. Within its priority project KENDA (Kilometer-Scale Ensemble Data Assimilation) the COSMO Consortium has developed an ensemble Kalman filter for data assimilation on the convective scale. It has been used operationally by MeteoSwiss and DWD since March 2017. An advantage of the ensemble data assimilation system is that the assimilation can be carried out based on the pure forward operator, and that it is not necessary to calculate derivatives of the forward operator or the adjoint tangential model for carrying out data assimilation. Also, it naturally introduces model increments for all variables where some dynamic covariance is observed from the underlying ensemble model runs. DWD aims to test the assimilation of ACL data into the COSMO-ART model based on BaLiFOp.

Data availability. The data for this paper can be made available upon request from the authors Armin Geisinger (armin.geisinger@uni-hohenheim.de), Andreas Behrendt (andreas.behrendt@uni-hohenheim.de), and Volker Wulfmeyer (volker.wulfmeyer@uni-hohenheim.de).

Competing interests. The authors declare that they have no conflict of interest.

Acknowledgements. The present study was part of the research project 50.0356/2012 funded by the German Federal Ministry of Transport and Digital Infrastructure (BMVI, prior BMVBS). We furthermore acknowledge the contributors to COSMO-ART, to the ceilometer network, to the IDL procedure mie_single, and to the Tmatrix codes we used as a basis for our study. We are also thankful for helpful discussions with Cristina Charlton-Perez, Ina Mattis, Werner Thomas, and Frank Wagner. Furthermore, we would like to acknowledge the travel support and very interesting discussions within the framework of the European COST (Cooperation in Science and Technology) action towards operational ground-based profiling with ceilometers, Doppler lidars, and microwave radiometers for improving weather forecasts (TOPROF).

Edited by: Andrew Sayer

Reviewed by: two anonymous referees

\section{References}

Ansmann, A., Tesche, M., Groß, S., Freudenthaler, V., Seifert, P., Hiebsch, A., Schmidt, J., Wandinger, U., Mattis, I., Müller, D., and Wiegner, M.: The 16 April 2010 major volcanic ash plume over central Europe: EARLINET lidar and AERONET photometer observations at Leipzig and Munich, Germany, Geophys. Res. Lett., 37, L13810, https://doi.org/10.1029/2010GL043809, 2010.

Bangert, M., Nenes, A., Vogel, B., Vogel, H., Barahona, D., Karydis, V. A., Kumar, P., Kottmeier, C., and Blahak, U.: Saharan dust event impacts on cloud formation and radiation over Western Europe, Atmos. Chem. Phys., 12, 4045-4063, https://doi.org/10.5194/acp-12-4045-2012, 2012.

Banta, R. M., Brewer, W. A., Sandberg, S. P., and Hardesty, R. M.: Doppler Lidar-Based Wind-Profile Measurement System for Offshore Wind-Energy and Other Marine Boundary Layer Applications, J. Appl. Meteorol. Clim., 51, 327-349, https://doi.org/10.1175/JAMC-D-11-040.1, 2012.

Behrendt, A., Nakamura, T., Onishi, M., Baumgart, R., and Tsuda, T.: Combined Raman lidar for the measurement of atmospheric temperature, water vapor, particle extinction coefficient, and particle backscatter coefficient, Appl. Opt., 41, 7657-7666, https://doi.org/10.1364/AO.41.007657, 2002.

Behrendt, A., Pal, S., Wulfmeyer, V., Álvaro M. Valdebenito B., and Lammel, G.: A novel approach for the characterization of transport and optical properties of aerosol particles near sources - Part I: Measurement of particle backscatter coefficient maps with a scanning UV lidar, Atmos. Environ., 45, 2795-2802, https://doi.org/10.1016/j.atmosenv.2011.02.061, 2011.

Benedetti, A. E. A.: Aerosol analysis and forecast in the European Centre for Medium-Range Weather Forecasts Integrated Forecast System: 2. Data assimilation, J. Geophys. Res., 114, D13205, https://doi.org/10.1029/2008JD011115, 2009.

Buchholtz, A.: Rayleigh-scattering calculations for the terrestrial atmosphere, OSA Proc., 34, 2765-2773, 1995.

Chaboureau, J.-P., Richard, E., Pinty, J.-P., Flamant, C., Di Girolamo, P., Kiemle, C., Behrendt, A., Chepfer, H., Chiriaco, M., and Wulfmeyer, V.: Long-range transport of Saharan dust and its radiative impact on precipitation forecast: a case study during the Convective and Orographically-induced Precipitation Study (COPS), Q. J. Roy. Meteor. Soc., 137, 236-251, https://doi.org/10.1002/qj.719 2011.

Charlton-Perez, C. L., Cox, O., Ballard, S. P., and Klugmann, D. A Forward model for atmospheric backscatter due to aerosols, clouds and rain, EMS Annual Meeting Abstracts, vol. 10 of EMS2013-313, 9-13 September 2013, Reading, UK, 2013.

Chen, S., Zhao, C., Qian, Y., Leung, L. R., Huang, J., Huang, Z., Bi, J., Zhang, W., Shi, J., Yang, L., Li, D., and Li, J.: Regional modeling of dust mass balance and radiative forc- 
ing over East Asia using WRF-Chem, Aeolian Res., 15, 15-30, https://doi.org/10.1016/j.aeolia.2014.02.001, 2014.

Cuevas, E., Camino, C., Benedetti, A., Basart, S., Terradellas, E., Baldasano, J. M., Morcrette, J. J., Marticorena, B., Goloub, P., Mortier, A., Berjón, A., Hernández, Y., Gil-Ojeda, M., and Schulz, M.: The MACC-II 2007-2008 reanalysis: atmospheric dust evaluation and characterization over northern Africa and the Middle East, Atmos. Chem. Phys., 15, 3991-4024, https://doi.org/10.5194/acp-15-3991-2015, 2015.

Dacre, H. F., Grant, A. L. M., and Johnson, B. T.: Aircraft observations and model simulations of concentration and particle size distribution in the Eyjafjallajökull volcanic ash cloud, Atmos. Chem. Phys., 13, 1277-1291, https://doi.org/10.5194/acp13-1277-2013, 2013.

Weitkamp, C.: Lidar: Range-Resolved Optical Remote Sensing of the Atmosphere, Springer Series in Optical Sciences, 455 pp., 2008.

Draine, B. T. and Flatau, P. J.: Discrete-Dipole Approximation For Scattering Calculations, J. Opt. Soc. Am. A, 11, 1491-1499, https://doi.org/10.1364/JOSAA.11.001491, 1994.

Emeis, S., Schäfer, K., and Münkel, C.: Observation of the structure of the urban boundary layer with different ceilometers and validation by RASS data, Meteorol. Z., 18, 149-154, https://doi.org/10.1127/0941-2948/2009/0365, 2009.

Emeis, S., Forkel, R., Junkermann, W., Schäfer, K., Flentje, H., Gilge, S., Fricke, W., Wiegner, M., Freudenthaler, V., Groß, S., Ries, L., Meinhardt, F., Birmili, W., Münkel, C., Obleitner, F., and Suppan, P.: Measurement and simulation of the 16/17 April 2010 Eyjafjallajökull volcanic ash layer dispersion in the northern Alpine region, Atmos. Chem. Phys., 11, 2689-2701, https://doi.org/10.5194/acp-11-2689-2011, 2011.

Flentje, H., Claude, H., Elste, T., Gilge, S., Köhler, U., PlassDülmer, C., Steinbrecht, W., Thomas, W., Werner, A., and Fricke, W.: The Eyjafjallajökull eruption in April 2010 - detection of volcanic plume using in-situ measurements, ozone sondes and lidar-ceilometer profiles, Atmos. Chem. Phys., 10, 10085-10092, https://doi.org/10.5194/acp-10-10085-2010, 2010a.

Flentje, H., Heese, B., Reichardt, J., and Thomas, W.: Aerosol profiling using the ceilometer network of the German Meteorological Service, Atmos. Meas. Tech. Discuss., https://doi.org/10.5194/amtd-3-3643-2010, 2010b.

Gasteiger, J., Groß, S., Freudenthaler, V., and Wiegner, M.: Volcanic ash from Iceland over Munich: mass concentration retrieved from ground-based remote sensing measurements, Atmos. Chem. Phys., 11, 2209-2223, https://doi.org/10.5194/acp11-2209-2011, 2011 a.

Gasteiger, J., Wiegner, M., Groß, S., Freudenthaler, V., Toledano, C., Tesche, M., and Kandler, K.: Modelling lidar-relevant optical properties of complex mineral dust aerosols, Tellus B, 63, 725741, https://doi.org/10.1111/j.1600-0889.2011.00559.x, 2011 b.

Haarig, M., Engelmann, R., Ansmann, A., Veselovskii, I., Whiteman, D. N., and Althausen, D.: $1064 \mathrm{~nm}$ rotational Raman lidar for particle extinction and lidar-ratio profiling: cirrus case study, Atmos. Meas. Tech., 9, 4269-4278, https://doi.org/10.5194/amt9-4269-2016, 2016.

Hammann, E., Behrendt, A., Le Mounier, F., and Wulfmeyer, V.: Temperature profiling of the atmospheric boundary layer with rotational Raman lidar during the $\mathrm{HD}(\mathrm{CP})^{2}$ Observational
Prototype Experiment, Atmos. Chem. Phys., 15, 2867-2881, https://doi.org/10.5194/acp-15-2867-2015, 2015.

Kemppinen, O., Nousiainen, T., Merikallio, S., and Räisänen, P.: Retrieving microphysical properties of dust-like particles using ellipsoids: the case of refractive index, Atmos. Chem. Phys., 15, 11117-11132, https://doi.org/10.5194/acp-15-11117-2015, 2015.

Kokkalis, P., Papayannis, A., Amiridis, V., Mamouri, R. E., Veselovskii, I., Kolgotin, A., Tsaknakis, G., Kristiansen, N. I., Stohl, A., and Mona, L.: Optical, microphysical, mass and geometrical properties of aged volcanic particles observed over Athens, Greece, during the Eyjafjallajökull eruption in April 2010 through synergy of Raman lidar and sunphotometer measurements, Atmos. Chem. Phys., 13, 9303-9320, https://doi.org/10.5194/acp-13-9303-2013, 2013.

Lange, A. C. and Elbern, H.: Lidar data assimilation for improved analyses of volcanic aerosol events, EGU General Assembly, EGU2014, Vienna, Austria, 27 April 2014-2 May, 16 2014, EGU2014-5987, 2014

Lathem, T. L., Kumar, P., Nenes, A., Dufek, J., Sokolik, I. N., Trail, M., and Russell, A.: Hygroscopic Properties of Volcanic Ash, Geophys. Res. Lett., 38, L11802, https://doi.org/10.1029/2011GL047298, 2011.

Madonna, F., Amodeo, A., D’Amico, G., and Pappalardo, G.: A study on the use of radar and lidar for characterizing ultragiant aerosol, J. Geophys. Res.-Atmos., 118, 10056-10071, https://doi.org/10.1002/jgrd.50789, 2013.

Mallet, M., Tulet, P., Serça, D., Solmon, F., Dubovik, O., Pelon, J., Pont, V., and Thouron, O.: Impact of dust aerosols on the radiative budget, surface heat fluxes, heating rate profiles and convective activity over West Africa during March 2006, Atmos. Chem. Phys., 9, 7143-7160, https://doi.org/10.5194/acp-9-7143-2009, 2009.

Mamouri, R. E., Papayannis, A., Amiridis, V., Müller, D., Kokkalis, P., Rapsomanikis, S., Karageorgos, E. T., Tsaknakis, G., Nenes, A., Kazadzis, S., and Remoundaki, E.: Multi-wavelength Raman lidar, sun photometric and aircraft measurements in combination with inversion models for the estimation of the aerosol optical and physico-chemical properties over Athens, Greece, Atmos. Meas. Tech., 5, 1793-1808, https://doi.org/10.5194/amt-5-17932012, 2012.

Matthias, V., Aulinger, A., Bieser, J., Cuesta, J., Geyer, B., Langmann, B., Serikov, I., Mattis, I., Minikin, A., Mona, L., Quante, M., Schumann, U., and Weinzierl, B.: The ash dispersion over Europe during the Eyjafjallajökull eruption - Comparison of CMAQ simulations to remote sensing and air-borne in-situ observations, Atmos. Environ., 48, 184-194, https://doi.org/10.1016/j.atmosenv.2011.06.077, 2012.

Mie, G.: Beiträge zur Optik trüber Median, speziell kolloidaler Metallösungen, Ann. Phys.-Berlin, 330, 377-445, https://doi.org/10.1002/andp.19083300302, 1908.

Mishchenko, M. I. and Travis, L. D.: Capabilities And Limitations Of A Current Fortran Implementation Of The 1-matrix Method For Randomly Oriented, Rotationally Symmetric Scatterers, J. Quant. Spectrosc. Ra., 60, 309-324, 1998.

Mishchenko, M. I., Travis, L. D., and Lacis, A. A.: Scattering, Absorption, and Emission of Light by Small Particles, Cambridge University Press, 2002. 
Mona, L., Amodeo, A., D’Amico, G., Giunta, A., Madonna, F., and Pappalardo, G.: Multi-wavelength Raman lidar observations of the Eyjafjallajökull volcanic cloud over Potenza, southern Italy, Atmos. Chem. Phys., 12, 2229-2244, https://doi.org/10.5194/acp-12-2229-2012, 2012.

Morcrette, J.-J., Boucher, O., Jones, L., Salmond, D., Bechtold, P., Beljaars, A., Benedetti, A., Bonet, A., Kaiser, J. W., Razinger, M., Schulz, M., Serrar, S., Simmons, A. J., Sofiev, M., Suttie, M., Tompkins, A. M., and Untch, A.: Aerosol analysis and forecast in the European Centre for Medium-Range Weather Forecasts Integrated Forecast System: Forward modeling, J. Geophys. Res.Atmos., 114, D06206, https://doi.org/10.1029/2008JD011235, 2009

Mortier, A., Goloub, P., Podvin, T., Deroo, C., Chaikovsky, A., Ajtai, N., Blarel, L., Tanre, D., and Derimian, Y.: Detection and characterization of volcanic ash plumes over Lille during the Eyjafjallajökull eruption, Atmos. Chem. Phys., 13, 3705-3720, https://doi.org/10.5194/acp-13-3705-2013, 2013.

Pappalardo, G., Amodeo, A., Apituley, A., Comeron, A., Freudenthaler, V., Linné, H., Ansmann, A., Bösenberg, J., D’Amico, G., Mattis, I., Mona, L., Wandinger, U., Amiridis, V., AladosArboledas, L., Nicolae, D., and Wiegner, M.: EARLINET: towards an advanced sustainable European aerosol lidar network, Atmos. Meas. Tech., 7, 2389-2409, https://doi.org/10.5194/amt7-2389-2014, 2014.

Radlach, M., Behrendt, A., and Wulfmeyer, V.: Scanning rotational Raman lidar at $355 \mathrm{~nm}$ for the measurement of tropospheric temperature fields, Atmos. Chem. Phys., 8, 159-169, https://doi.org/10.5194/acp-8-159-2008, 2008.

Rieger, D., Bangert, M., Kottmeier, C., Vogel, H., and Vogel, B.: Impact of aerosol on post-frontal convective clouds over Germany, Tellus B, 66, 22528, https://doi.org/10.3402/tellusb.v66.22528, 2014.

Rocha-Lima, A., Martins, J. V., Remer, L. A., Krotkov, N. A., Tabacniks, M. H., Ben-Ami, Y., and Artaxo, P.: Optical, microphysical and compositional properties of the Eyjafjallajökull volcanic ash, Atmos. Chem. Phys., 14, 10649-10661, https://doi.org/10.5194/acp-14-10649-2014, 2014.

Sandrini, S., Giulianelli, L., Decesari, S., Fuzzi, S., Cristofanelli, P., Marinoni, A., Bonasoni, P., Chiari, M., Calzolai, G., Canepari, S., Perrino, C., and Facchini, M. C.: In situ physical and chemical characterisation of the Eyjafjallajökull aerosol plume in the free troposphere over Italy, Atmos. Chem. Phys., 14, 1075-1092, https://doi.org/10.5194/acp-14-1075-2014, 2014.

Schumann, U., Weinzierl, B., Reitebuch, O., Schlager, H., Minikin, A., Forster, C., Baumann, R., Sailer, T., Graf, K., Mannstein, H., Voigt, C., Rahm, S., Simmet, R., Scheibe, M., Lichtenstern, M., Stock, P., Rüba, H., Schäuble, D., Tafferner, A., Rautenhaus, M., Gerz, T., Ziereis, H., Krautstrunk, M., Mallaun, C., Gayet, J.F., Lieke, K., Kandler, K., Ebert, M., Weinbruch, S., Stohl, A., Gasteiger, J., Groß, S., Freudenthaler, V., Wiegner, M., Ansmann, A., Tesche, M., Olafsson, H., and Sturm, K.: Airborne observations of the Eyjafjalla volcano ash cloud over Europe during air space closure in April and May 2010, Atmos. Chem. Phys., 11, 2245-2279, https://doi.org/10.5194/acp-11-2245-2011, 2011

Shipley, S. T., Tracy, D. H., Eloranta, E. W., Trauger, J. T., Sroga, J. T., Roesler, F. L., and Weinman, J. A.: High spectral resolution lidar to measure optical scattering properties of atmospheric aerosols. 1: Theory and instrumentation, Appl. Opt., 22, 37163724, https://doi.org/10.1364/AO.22.003716, 1983.

Sič, B.: Amélioration de la représentation des aérosols dans un modèle de chimie-transport: Modélisation et assimilation de donnèes, $\mathrm{PhD}$ thesis, Université Toulouse, 2014.

Späth, F., Behrendt, A., Muppa, S. K., Metzendorf, S., Riede, A., and Wulfmeyer, V.: 3-D water vapor field in the atmospheric boundary layer observed with scanning differential absorption lidar, Atmos. Meas. Tech., 9, 1701-1720, https://doi.org/10.5194/amt-9-1701-2016, 2016.

Strohbach, J.: Ausbreitung der Eyjafjallajökull-Vulkanasche im April 2010 über Deutschland: Reanalyse der Ceilometermessungen des Deutschen Wetterdienstes, Bachelor Thesis, University of Hohenheim, 2015.

Sugimoto, N., Matsui, I., Shimizu, A., Nishizawa, T., Hara, Y., Xie, C., Uno, I., Yumimoto, K., Wang, Z., and Yoon, S.-C.: Lidar network observations of tropospheric aerosols, Proc. SPIE 7153, Lidar Remote Sensing for Environmental Monitoring IX, 71530A https://doi.org/10.1117/12.806540, 2008.

Turner, D. D., Ferrare, R. A., Heilman Brasseur, L. A., Feltz, W. F., and Tooman, T. P.: Automated Retrievals of Water Vapor and Aerosol Profiles from an Operational Raman Lidar, J. Atmos. Ocean. Tech., 19, 37-50, https://doi.org/10.1175/15200426(2002)019<0037:AROWVA>2.0.CO;2, 2002.

Valdebenito B, A. M., Pal, S., Behrendt, A., Wulfmeyer, V., and Lammel, G.: A novel approach for the characterisation of transport and optical properties of aerosol particles near sources - Part II: Microphysics-chemistry-transport model development and application, Atmos. Environ., 45, 2981-2990, https://doi.org/10.1016/j.atmosenv.2010.09.004, 2011.

Vogel, B., Vogel, H., Bäumer, D., Bangert, M., Lundgren, K., Rinke, R., and Stanelle, T.: The comprehensive model system COSMOART - Radiative impact of aerosol on the state of the atmosphere on the regional scale, Atmos. Chem. Phys., 9, 8661-8680, https://doi.org/10.5194/acp-9-8661-2009, 2009.

Vogel, H., Förstner, J., Vogel, B., Hanisch, T., Mühr, B., Schättler, U., and Schad, T.: Time-lagged ensemble simulations of the dispersion of the Eyjafjallajökull plume over Europe with COSMO-ART, Atmos. Chem. Phys., 14, 7837-7845, https://doi.org/10.5194/acp-14-7837-2014, 2014.

Waquet, F., Peers, F., Goloub, P., Ducos, F., Thieuleux, F., Derimian, Y., Riedi, J., Chami, M., and Tanré, D.: Retrieval of the Eyjafjallajökull volcanic aerosol optical and microphysical properties from POLDER/PARASOL measurements, Atmos. Chem. Phys., 14, 1755-1768, https://doi.org/10.5194/acp14-1755-2014, 2014.

Whiteman, D. N., Melfi, S. H., and Ferrare, R. A.: Raman lidar system for the measurement of water vapor and aerosols in the Earth's atmosphere, Appl. Opt., 31, 3068-3082, https://doi.org/10.1364/AO.31.003068, 1992.

Wiegner, M., Madonna, F., Binietoglou, I., Forkel, R., Gasteiger, J., Geiß, A., Pappalardo, G., Schäfer, K., and Thomas, W.: What is the benefit of ceilometers for aerosol remote sensing? An answer from EARLINET, Atmos. Meas. Tech., 7, 1979-1997, https://doi.org/10.5194/amt-7-1979-2014, 2014.

Wiscombe, W. J.: Improved Mie scattering algorithms, OSA Proc., 19, 1505-1509, 1980.

Wolke, R., Hellmuth, O., Knoth, O., Schröder, W., Heinrich, B., and Renner, E.: Air Pollution Modeling and Its Application XVI, The 
Chemistry-Transport Modeling System lm-Muscat: Description and citydelta Applications, Springer US, Boston, MA, 427-439, https://doi.org/10.1007/978-1-4419-8867-6_39, 2004.

Wulfmeyer, V. and Feingold, G.: On the relationship between relative humidity and particle backscattering coefficient in the marine boundary layer determined with differential absorption lidar, J. Geophys. Res.-Atmos., 105, 4729-4741, https://doi.org/10.1029/1999JD901030, 2000.

Wulfmeyer, V., Pal, S., Turner, D. D., and Wagner, E.: Can Water Vapour Raman Lidar Resolve Profiles of Turbulent Variables in the Convective Boundary Layer?, Bound.-Lay. Meteorol., 136, 253-284, https://doi.org/10.1007/s10546-010-9494-z, 2010.

Wulfmeyer, V., Hardesty, R. M., Turner, D. D., Behrendt, A., Cadeddu, M. P., Di Girolamo, P., Schlüssel, P., Van Baelen, J., and Zus, F.: A review of the remote sensing of lower tropospheric thermodynamic profiles and its indispensable role for the understanding and the simulation of water and energy cycles, Rev. Geophys., 53, 819-895, https://doi.org/10.1002/2014RG000476, 2015.
Young, A. T.: Rayleigh scattering, OSA Proc., 20, 533-535, 1981.

Zakey, A. S., Solmon, F., and Giorgi, F.: Implementation and testing of a desert dust module in a regional climate model, Atmos. Chem. Phys., 6, 4687-4704, https://doi.org/10.5194/acp-6-46872006, 2006.

Zakšek, K., Hort, M., Zaletelj, J., and Langmann, B.: Monitoring volcanic ash cloud top height through simultaneous retrieval of optical data from polar orbiting and geostationary satellites, Atmos. Chem. Phys., 13, 2589-2606, https://doi.org/10.5194/acp13-2589-2013, 201 